OPEN ACCESS

Edited by:

Chongyu Zhu,

Fudan University, China

Reviewed by:

Wei-Min Ren,

Dalian University of Technology, China

Charles Romain

Imperial College London,

United Kingdom

${ }^{*}$ Correspondence:

Yunqing Zhu

1019zhuyq@tongji.edu.cn

orcid.org/0000-0002-2557-003X

Specialty section:

This article was submitted to

Polymer Chemistry,

a section of the journal

Frontiers in Chemistry

Received: 29 December 2020 Accepted: 23 February 2021

Published: 20 April 2021

Citation:

Liang X, Tan F and Zhu Y (2021)

Recent Developments in

Ring-Opening Copolymerization of

Epoxides With $\mathrm{CO}_{2}$ and Cyclic

Anhydrides for Biomedical

Applications. Front. Chem. 9:647245.

doi: 10.3389/fchem.2021.647245

\section{Recent Developments in} Ring-Opening Copolymerization of Epoxides With $\mathrm{CO}_{2}$ and Cyclic Anhydrides for Biomedical Applications

\author{
Xue Liang ${ }^{1}$, Fei $\operatorname{Tan}^{2,3}$ and Yunqing Zhu ${ }^{1,4 *}$ \\ ${ }^{1}$ School of Materials Science and Engineering, Tongji University, Shanghai, China, ${ }^{2}$ Department of Orthopedics, Shanghai \\ Tenth People's Hospital, Tongji University School of Medicine, Shanghai, China, ${ }^{3}$ Department of Otorhinolaryngology-Head \\ and Neck Surgery, Shanghai East Hospital, Shanghai, China, ${ }^{4}$ School of Medicine, Tongji University, Shanghai, China
}

The biomedical applications of polyesters and polycarbonates are of interest due to their potential biocompatibility and biodegradability. Confined by the narrow scope of monomers and the lack of controlled polymerization routes, the biomedical-related applications of polyesters and polycarbonates remain challenging. To address this challenge, ring-opening copolymerization (ROCOP) has been exploited to prepare new alternating polyesters and polycarbonates, which would be hard to synthesize using other controlled polymerization methods. This review highlights recent advances in catalyst development, including the emerging dinuclear organometallic complexes and metal-free Lewis pair systems. The post-polymerization modification methods involved in tailoring the biomedical functions of resultant polyesters and polycarbonates are summarized. Pioneering attempts for the biomedical applications of ROCOP polyesters and polycarbonates are presented, and the future opportunities and challenges are also highlighted.

Keywords: degradable polymers, Lewis pairs, biomedical applications, post-polymerization modifications, ring-opening copolymerization

\section{INTRODUCTION}

The polymerization of carbon dioxide $\left(\mathrm{CO}_{2}\right)$ with epoxides to form polycarbonate can maximize the use of $\mathrm{CO}_{2}$ to achieve value-adding benefits, in which polycarbonate has great potential for biomedical applications due to its excellent optical and mechanical properties, as well as good biocompatibility (Paul et al., 2015b; Cui et al., 2019; Ye et al., 2019). Compared with petroleum derivative monomers, bio-based monomers usually have more functional groups, and it is difficult to achieve highly selective polymerization through traditional polymerization methods (Stadler et al., 2019). For ring-opening copolymerization (ROCOP) of epoxide with $\mathrm{CO}_{2}$ or cyclic anhydrides, many efficient metal-based catalysts have been developed to produce alternating polycarbonates or polyesters (Paul et al., 2015b; Longo et al., 2016; Xia and Zhao, 2018; Liang et al., 2021), including zinc (Deacy et al., 2018, 2020a; Denk et al., 2020), cobalt (Li et al., 2017a; Ambrose et al., 2019), aluminum (Sanford et al., 2018), or nickel (Huang et al., 2017; Li et al., 2017a) complexes with different ligands. These organometallic catalysts exhibit excellent catalytic 


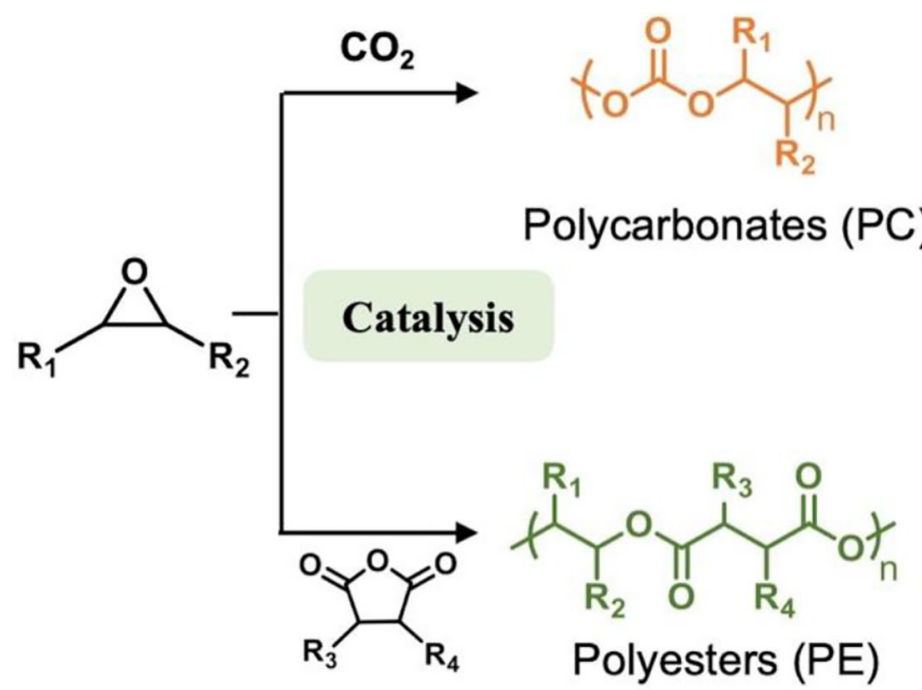

Post-polymerization modification

Thiol-ene reaction

Diels-Alder reaction

Hydroboration-oxidation reaction

Biomedical application

Drug delivery nanoparticles

Self-healing materials

Tumor imaging platforms

SCHEME 1 | Ring-opening copolymerization of epoxides with $\mathrm{CO}_{2}$ and cyclic anhydrides and post-polymerization modification for biomedical applications.

performance and high selectivity toward the formation of ester or carbonate linkages during polymerizations, showing reduced side reactions forming ether linkages or cyclic carbonates. In recent years, dinuclear metal catalysts have received widespread attention due to their higher catalytic efficiency than mononuclear catalysts (Yu et al., 2016; Garden et al., 2017), due to the synergy between metals (Cheng et al., 2019). Besides, many studies have shown that dinuclear catalysts usually showed an excellent catalytic activity even in the absence of cocatalysts (Kember and Williams, 2012; Saini et al., 2014).

Abbreviations: AGE, allyl glycidyl ether; BA, benzoate; $t$-BGE, tert-butyl glycidyl ether; BilBTP, bis(benzotriazolyliminophenolate); $\mathrm{BTA}$, butyrate; $t-\mathrm{BuP}_{1}$, tert-butyliminotris(dimethylamino)phosphorane; $\mathrm{CBO}$, cis-2,3-epoxybutane; trans-2,3-CBO, trans-2,3-butylene oxide; CDO, 1,4-dihydro-naphthalene oxide; CEO, 1,2-epoxy-4-cyclohexene; $\mathrm{CHC}$, cyclohexene carbonate; $\mathrm{CHO}$, cyclohexene oxide; Cl-SO, 4-chlorostyrene oxide; $\mathrm{CO}_{2}$, carbon dioxide; COPO, 3,4-epoxytetrahydrofuran; CPMA, carbic anhydride; CPO, cyclopentene oxide; trans-CSO, trans-stilbene oxide; $(S, S)$-CSO, rac-/(S,S)-trans-diethyl epoxysuccinate; rac-trans-CSO, rac-trans-stilbene oxide; trans-CTO, rac/(S,S)-trans-diethyl epoxysuccinate; CTPB, cyclic trimeric phosphazene base; DBU, 1,8-diazabicyclo[5.4.0] undec-7-ene; DFT, density functional theory; DHC, dihydrocoumarin; DIBTP, diamine-bis(benzotriazole phenolate); DGA, diglycolic anhydride; $\varepsilon$-DL, $\varepsilon$-decalactone; DMAP, 4-dimethylaminopyridine; 3,4-DMPA, 3,4-dimethyl phthalic anhydride; DPA, diphenic anhydride; DSC, differential scanning calorimetry; EC, ethylene carbonate; ECH, epichlorohydrin; GA, glutaric anhydride; GO, phenyl glycidyl ether; HA, hydrocinnamate; LA, Lewis acid; rac-LA, rac-lactide; LB, Lewis base; LLA-OCA, L-lactide-Ocarboxyanhydride; MA, maleic anhydride; MEA, monoethanolamine; NA, cis-5-norbornene-endo-2,3-dicarboxylic anhydride; 1,2-NA, 2-naphthalic anhydrides; PA, phthalic anhydride; PCHC, poly(cyclohexene carbonate); PCHPE, poly(cyclohexylene phthalate); PEC, poly(ethylene carbonate); PLA, poly lactide; PLLA- $b$-PCHC, poly(L-lactide- $b$-cyclohexene carbonate); PO, propylene oxide; $\mathrm{PPNCl}$, bis(triphenylphosphine)iminium chloride; ROP, ringopening polymerization; ROCOP, ring-opening copolymerization; SA, succinic anhydride; SO, styrene oxide; TCA, tricyclic anhydride; TEB, triethyl borane; TFPB, tris(pentafluorophenyl)borane; THPA, tetrahydrophthalic anhydride; TPB, triphenyl borane; TON, turnover number; TOF, turnover frequency; VCHO, vinyl cyclohexene oxide; VGE, vanillin glycidyl ether; VPO, vinyl propylene oxide.
Dinuclear metal catalysts generally exhibited a higher catalytic activity and selectivities as well as fewer side reactions, which could be advantageous for making biopolymers with well-defined chain structures.

Despite the fact that metal-based catalysts have shown excellent catalytic performance, there are also some problems such as complicated ligand design and synthesis procedure in order to reach high catalytic ability (Saini et al., 2014). In addition, the removal of residual metal substances in the system after the polymerization is also a problem that needs attention (Alferov et al., 2019). Residual trace of metal from organometallic catalysts may pose potential toxicity problems that limit their applications in biomedicine (Nachtergael et al., 2015). In order to overcome this issue, organic/metal-free catalysts with efficiency and selectivity/control have been extensively studied in the last decade (Lin et al., 2019; McGraw and Chen, 2020; Hong, 2021). The development of metal-free Lewis pair catalyst systems are considered an effective way. Li's team has developed a series of Lewis pair systems that display good catalytic ability and selectivity (Ji et al., 2018a,b; Ji et al., 2019; Wang et al., 2020). Li et al. successfully copolymerized phthalate with propylene/ethylene oxide at room temperature using a two-part catalyst containing phosphazene base and triethyl borane (TEB) to produce block copolymers with strict ABtype sequence structure and controlled molecular weights (Li et al., 2019a). Zhang et al. synthesized alternating copolymers with high molecular weights (up to $34 \mathrm{~kg} \cdot \mathrm{mol}^{-1}$ ) with metalfree Lewis pairs [phosphazene base $\left(t-\mathrm{BuP}_{1}\right)$ as the base and TEB as the acid; Zhang et al., 2020a]. Furthermore, no metal substance being introduced during the polymerization process could be an advantage to expand its application in biomedicine.

One of the limitations of ROCOP is that some functional groups are incompatible during the polymerization process, such as hydroxyl, primary or secondary amines, carboxylic acid, 


\section{Epoxides}

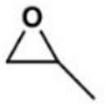

propylene oxide PO
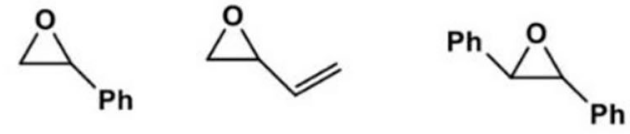

rac-trans-
rac-t

ac-trans-CSO

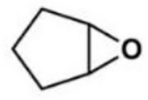

cyclopentene oxide $\mathrm{CPO}$<smiles>O=C1C=CC(=O)O1</smiles>

maleic anhydride MA

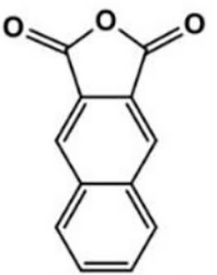

1,2-naphthalic anhydrides 1,2- NA<smiles>O=C1CCCC(=O)O1</smiles>

glutaric anhydride GA

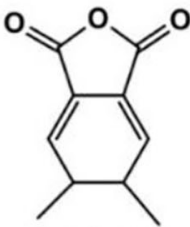

3,4-dimethyl phthalic anhydride 3,4-DMPA

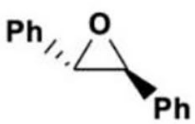

-/(S,S)-trans-diethyl epoxysuccinate (S,S)-CSO

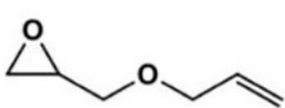

allyl glycidyl ether AGE
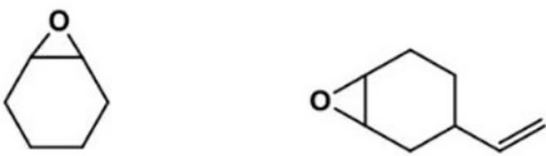

cyclohexene oxide $\mathrm{CHO}$

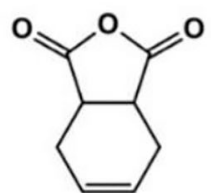

tetrahydro phthalic
THPA<smiles>O=C1CCC(=O)O1</smiles>

FIGURE 1

The structures of epoxides and anhydrides discussed in this review.

or other protonic functional groups, which could function as chain transfer agents, thereby affecting the molecular weight and distribution of the polymer. Besides, the coexistence of species with different degrees of functionality usually leads to broad or even multimodal molecular weight distributions, which also jeopardizes the chain-end fidelity. Moreover, excessive protonic functional groups may cause catalyst deactivation (Yi et al., 2019). Therefore, post-polymerization modification is an important means to realize multi-functionalities on ROCOP polymers, and the desired functional groups can be accurately connected to the polymer chain by different modification methods (Ntoukam et al., 2020). In addition, the functionalization of the polymer can be achieved without protecting and deprotecting processes for functional monomers. For instance, Sanford et al. incorporated both aldehyde and alkene functionalities into the polymer to achieve orthogonal post-polymerization modification in a one-pot process (Sanford et al., 2018).

Regarding the advantages of dinuclear complexes and metal-free Lewis pairs for making polymers with potential applications in biomedicine, this review focuses on the recent development of ROCOP of epoxides $/ \mathrm{CO}_{2}$ or cyclic anhydrides (Figure 1) to produce polycarbonates, polyesters, or copolymers, with novel homo- and heterodinuclear metal catalysts and metal-free Lewis pair catalyst systems. Furthermore, the postpolymerization functionalization of polycarbonates or polyesters 


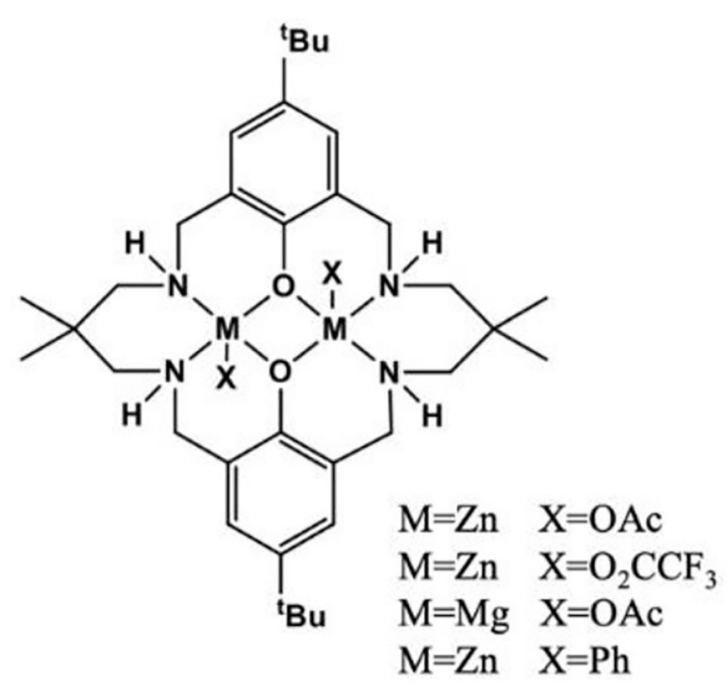

(1a)

(1b)

(1c)

(1d)

FIGURE 2 | The structures of various homodinuclear catalysts.

will be summarized, and the influence that multifunctionalities of polymer exert over potential biomedical applications will be emphasized (Scheme 1).

\section{CATALYST SYSTEMS}

\section{Homodinuclear Catalysts}

For the ROCOP, many types of mononuclear or dinuclear organometallic catalysts have been developed (Paul et al., 2015b; Longo et al., 2016). In order to achieve better catalytic efficiency, cocatalysts are usually required for mononuclear complexes (Paul et al., 2015b; Thevenon et al., 2018). However, for dinuclear complexes, the addition of cocatalysts can be avoided. Besides, bimetallic catalysts show good catalytic performance due to the synergy between the metal centers (Zhou et al., 2017). The Williams group has prepared a series of dizinc catalysts, including $\mathrm{LZn}_{2}(\mathrm{X})_{2}\left[\mathrm{X}=\mathrm{OAc}, \mathrm{O}_{2} \mathrm{CCF}_{3}\right.$, phenyl $\left.(\mathrm{Ph})\right]$ (Romain and Williams, 2014; Thevenon et al., 2015; Yi et al., 2015; Romain et al., 2017) coordinated by a macrocyclic ligand (Figure 2), which exhibits excellent catalytic efficiency and high selectivity for ROCOP of $\mathrm{CO}_{2}$ and epoxides at relatively low $\mathrm{CO}_{2}$ pressure $(\sim 1$ bar $)$. In 2015 , they used the waste $\mathrm{CO}_{2}$ to carry out a copolymerization experiment with cyclohexene oxide $(\mathrm{CHO})$, using $\mathrm{LZn}_{2}(\mathrm{OAc})_{2}, \mathrm{LMg}_{2}(\mathrm{OAc})_{2}$, and $\mathrm{LZn}_{2}\left(\mathrm{O}_{2} \mathrm{CCF}_{3}\right)$ as the catalysts. These catalysts showed good tolerance, even if the $\mathrm{CO}_{2}$ was contaminated by compounds containing $\mathrm{S}-\mathrm{H}$ $\left(\mathrm{H}_{2} \mathrm{~S}\right.$, octadecanethiol), $\mathrm{N}-\mathrm{H}$ [diethylamine, monoethanolamine (MEA)], and $\mathrm{O}-\mathrm{H}\left(\mathrm{H}_{2} \mathrm{O}, \mathrm{MEA}, \mathrm{SO}_{2}\right)$ groups (Chapman et al., 2015).

Multiblock copolymers usually consist of different polymer blocks that are covalently bonded to each other (Yoshida and Takenaka, 2015), which combines different properties exhibited by each block to improve the performance and functionality. One-pot synthesis could be an effective method to develop block polymers, and the key is to control the growth sequence of polymer chains to obtain predictable and well-defined copolymers. In 2008, Coates and co-works used (bdi)ZnOAc complex to catalyze the one-pot terpolymerization of epoxide, anhydride, and $\mathrm{CO}_{2}$ to afford block copolymers. Kinetic studies suggested a highly selective product-determining step (Jeske et al., 2008). In 2014, a new type of chemoselective control has been proposed by Williams. In the process of ring-opening polymerization (ROP) and ROCOP, it can selectively synthesize polyesters and polycarbonates (Romain and Williams, 2014; Paul et al., 2015a).

In previous studies on chemoselective polymerization, both $\mathrm{AB}$ and $\mathrm{ABA}$ type block were formed, resulting in bimodal molecular weight distributions of the copolymer (Romain and Williams, 2014). In order to avoid this issue, the $\mathrm{LZn}_{2} \mathrm{Ph}_{2}$ catalyst was proposed to catalyze ROCOP of $\mathrm{CHO} /$ phthalic anhydride (PA), in the presence of cyclohexane diol as the initiator. As the phenyl co-ligand was hydrolyzed by cyclohexane diol during initiation, the obtained poly(cyclohexylene phthalate) (PCHPE) featured a dihydroxyl telechelic structure. In the terpolymerization, the ROCOP of $\mathrm{CHO} / \mathrm{PA}$ occurred before the ROP of $\varepsilon$-decalactone $(\varepsilon-\mathrm{DL})$ to form pure PCHPE. After PA was completely consumed, the ROP of $\varepsilon$-DL was activated. Given the fact that first formed PCHPE featured a dihydroxyl telechelic structure, ABA type block (PDL- $b$ PCHPE- $b$-PDL) was formed at the end of polymerization (Zhu et al., 2015). Then, the chemoselective concept was extended to the tetrapolymerization of epoxide, lactone, cyclic anhydride, and $\mathrm{CO}_{2}$, demonstrating that $\mathrm{LZn}_{2}(\mathrm{OAc})_{2}$ catalysts can switch between different polymerization cycles and exhibit high monomer selectivity (Romain et al., 2016). In particular, $\mathrm{LZn}_{2}(\mathrm{OAc})_{2}$ and $\mathrm{LMg}_{2}(\mathrm{OAc})_{2}$ catalysts showed opposite selectivity in the ROCOP of $\mathrm{CHO} / \mathrm{BCA} 1 / \mathrm{CO}_{2}$ to prepared copolymers, where BCA1 is a tricyclic bio-derived anhydride usually synthesized via Diels-Alder reaction between $\alpha$-phellandrene and maleic anhydride (MA) (Figure 3). When $\mathrm{LZn}_{2}(\mathrm{OAc})_{2}$ was added to reaction, the ROCOP of $\mathrm{CHO}$ and BCA1 occurred first. Then after the complete consumption of BCA1, the ROCOP of $\mathrm{CHO} / \mathrm{CO}_{2}$ started to initiate, leading to the formation of poly(ester- $b$-carbonate). Contrarily, when $\mathrm{LMg}_{2}(\mathrm{OAc})_{2}$ was used, the ROCOP of $\mathrm{CHO}$ and $\mathrm{CO}_{2}$ occurred first, and only upon the removal of $\mathrm{CO}_{2}$ was the ROCOP of $\mathrm{CHO} / \mathrm{BCA} 1$ able to initiate to afford poly(carbonate- $b$-ester) (Saini et al., 2017). This opposite selectivity is due to the fact that $\mathrm{LZn}_{2}(\mathrm{OAc})_{2}$ and $\mathrm{LMg}_{2}(\mathrm{OAc})_{2}$ catalysts have different reaction orders in the anhydride.

Recently, chemoselective polymerization was further extended to the terpolymerization of $O$-carboxyanhydride, $\mathrm{CHO}$, and $\mathrm{CO}_{2}$, to prepare PLA- $b$-PCHC. This strategy is different from that of the previous studies, making PLA- $b$-PCHC by sequential addition method or tandem catalysis. Instead, two different polymerization cycles are coupled together by a one-pot synthetic strategy with $\mathrm{LZn}_{2}(\mathrm{OAc})_{2}$ as the only catalyst. The PLLA was prepared by the ROP of L-lactide- $O$-carboxyanhydride (LLA-OCA), and then the $\mathrm{CO}_{2}$, released by OCA during its ROP, was cooperated with $\mathrm{CHO}$ to synthesize PCHC blocks by ROCOP (Figure 4). In this reaction, ROCOP happened after the ROP of LLA-OCA, and the IR signals representing PCHC increase after the LLA-OCA was completely consumed. Up to 


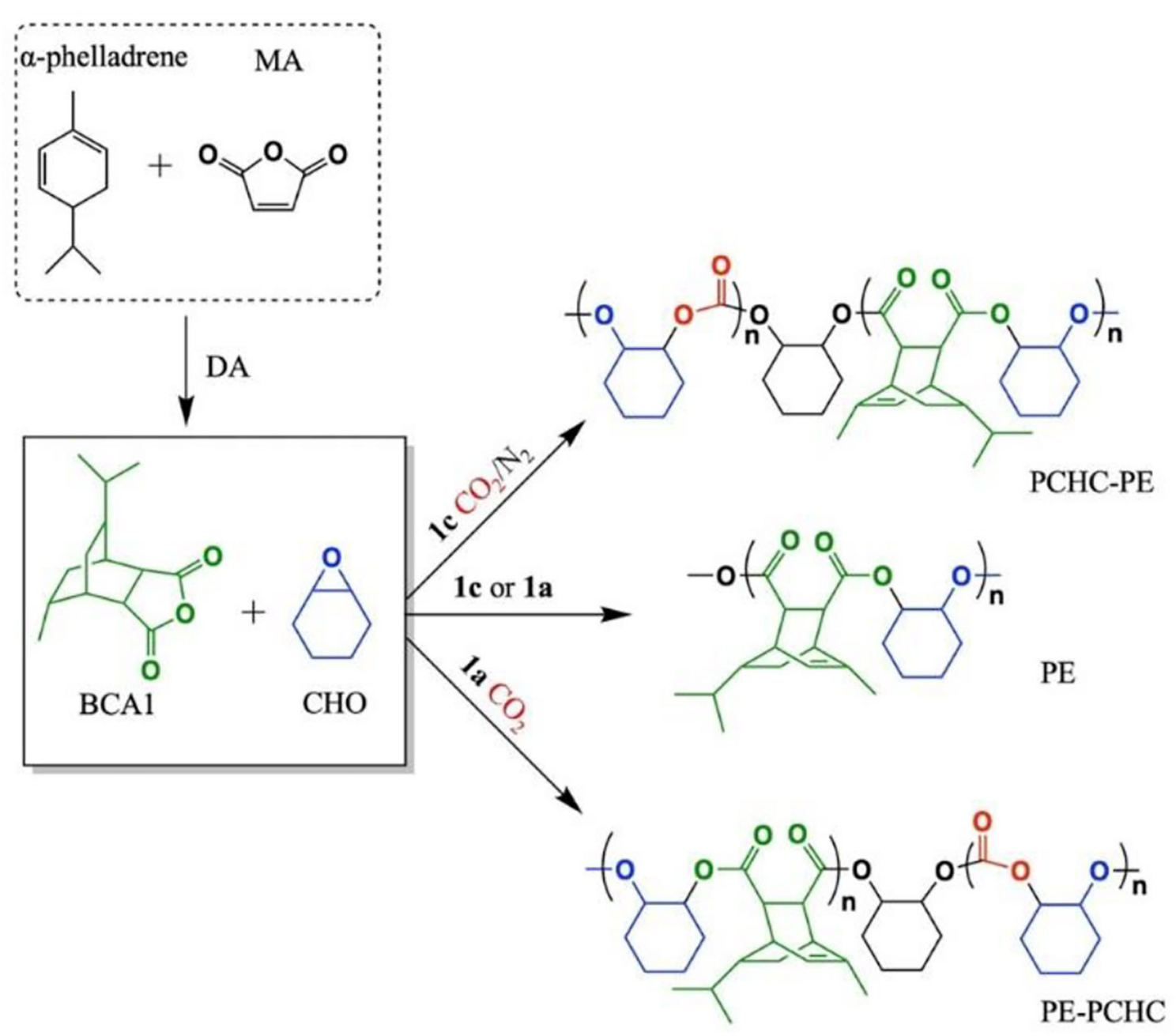

FIGURE 3 | Polyesters and block copolymers based on the bio-derived anhydride, BCA1, were produced using catalysts $L \mathrm{Zn}_{2}(\mathrm{OAc})_{2}(\mathbf{1 a})$ and $L M g_{2}(\mathrm{OAc})_{2}(\mathbf{1 c})$. The images are reproduced from Saini et al. (2017).

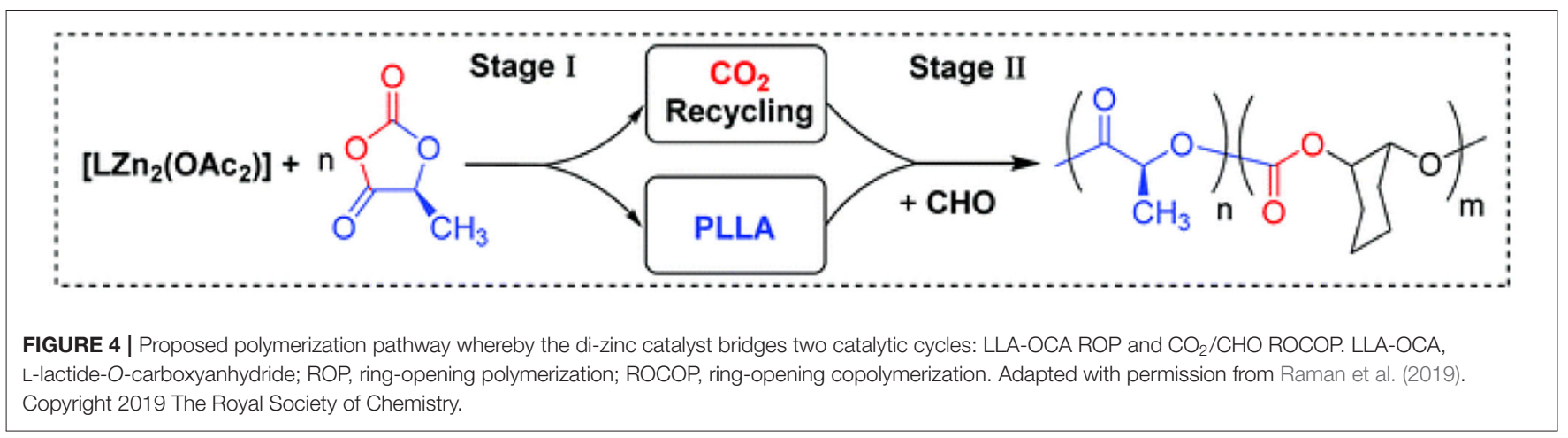

$91 \%$ of the $\mathrm{CO}_{2}$ was incorporated into block copolymers, with only $9 \%$ forming cyclic carbonate due to the backbiting of the polymer chain (Raman et al., 2019).

Lara-Sanchez and co-workers prepared a series of dinuclear zinc catalysts using scorpionate ligands (Figure 5) for the
ROCOP of epoxides and $\mathrm{CO}_{2}$ to form random polycarbonates. In catalysts $\mathbf{2}$ (Martínez et al., 2016) and $\mathbf{3}$ (de la Cruz-Martinez et al., 2020), the heteroscorpionate ligand is coordinated to a zinc center by $\kappa^{3}$-NNO coordination mode, three acetate co-ligands bridging the 2 six- and four-coordination zinc 

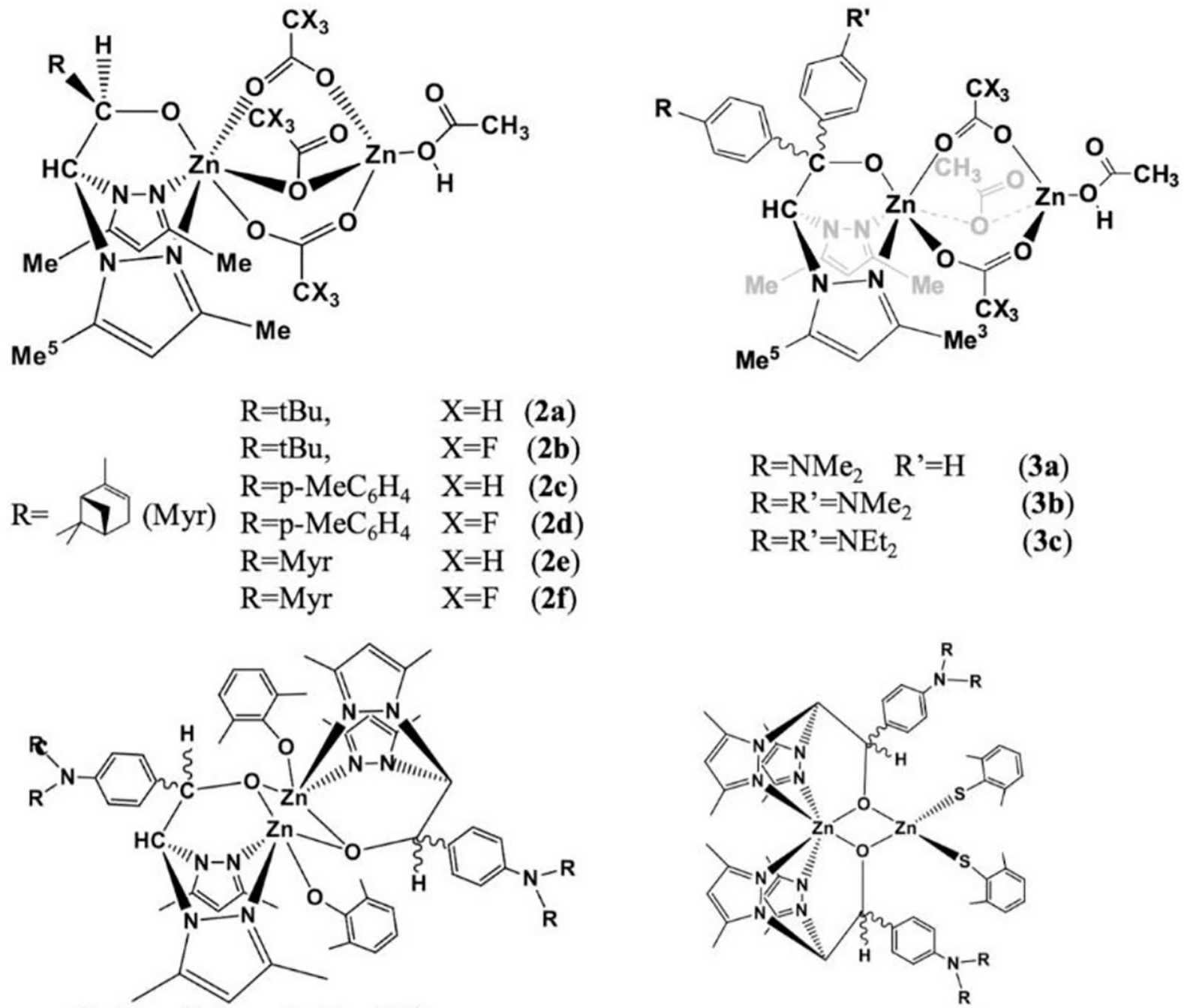

$\mathrm{R}=\mathrm{Me} \quad$ (4a) $\quad \mathrm{R}=\mathrm{Et} \quad$ (4b)

$\mathrm{R}=\mathrm{Me} \quad$ (5a) $\quad \mathrm{R}=\mathrm{Et}$
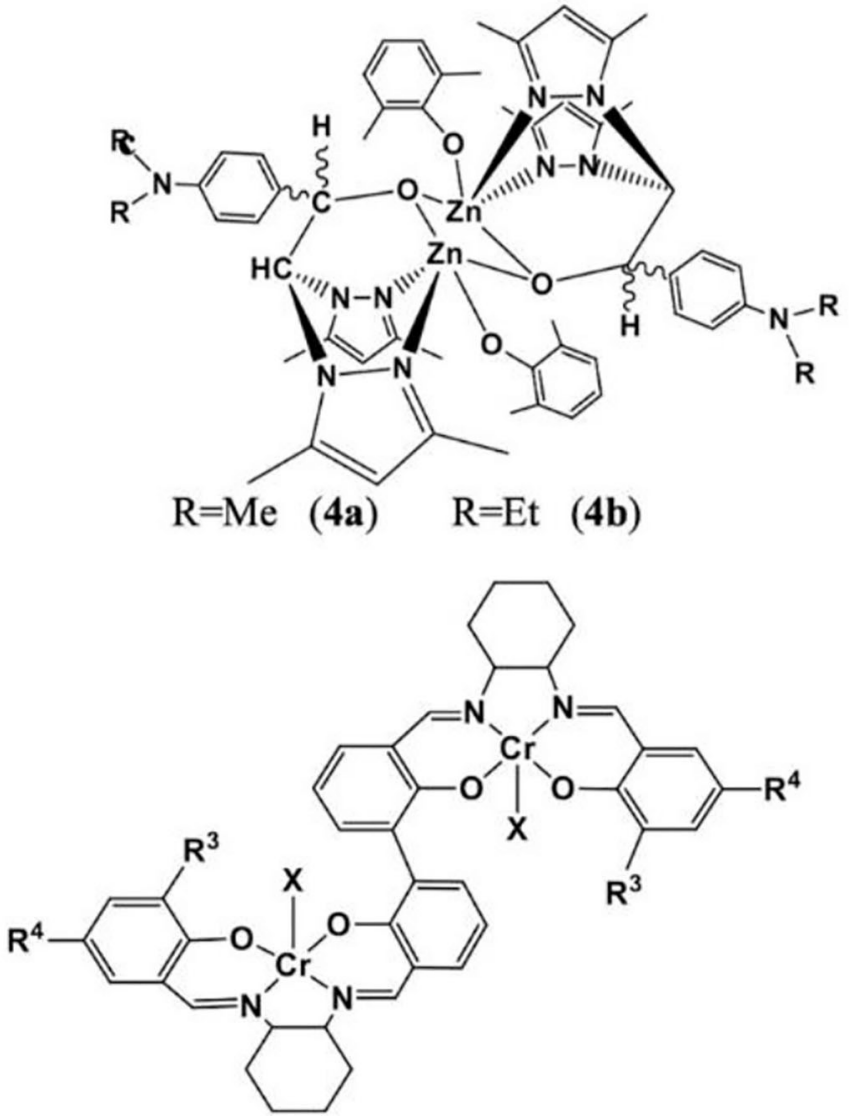

$$
\begin{array}{lll}
\mathrm{X}=\mathrm{Cl} & \mathrm{R}^{3}=\mathrm{R}^{4}=\mathrm{t} \mathrm{Bu} & \\
\mathrm{X}=\mathrm{NO}_{3} & \mathrm{R}^{3}=\mathrm{R}^{4}={ }^{\mathrm{t}} \mathrm{Bu} & \\
\mathrm{X}=\mathrm{N}_{3} & \mathrm{R}^{3}=\mathrm{R}^{4}={ }^{\mathrm{t}} \mathrm{Bu} & \\
\mathrm{X}=\mathrm{Cl} & \mathrm{R}^{3}={ }^{\mathrm{t}} \mathrm{Bu} & \mathrm{R}^{4}=\mathrm{MeO} \\
\mathrm{X}=\mathrm{Cl} & \mathrm{R}^{3}=\mathrm{B} \mathrm{Bu} & \mathrm{R}^{4}=\mathrm{F} \\
\mathrm{X}=\mathrm{Cl} & \mathrm{R}^{3}=\mathrm{Me} & \mathrm{R}^{4}=\mathrm{F} \\
\mathrm{X}=\mathrm{Cl} & \mathrm{R}^{3}=\mathrm{H} & \mathrm{R}^{4}=\mathrm{F}
\end{array}
$$

FIGURE $\mathbf{5}$ | The structures of the catalysts 2-6 based on scorpionate ligand.

centers. The ROCOP of $\mathrm{CO}_{2}$ and $\mathrm{CHO}$ was carried out under solvent-free, cocatalyst-free, optimal reaction temperature, and $\mathrm{CO}_{2}$ pressure. It was found that all catalysts can initiate copolymerization without the presence of co-catalysts. Among them, catalyst 2 e showed the highest catalytic activity $[89 \%$ conversion, turnover frequency (TOF) up to $5.56 \mathrm{~h}^{-1}$ ], carbonate 


\section{$C 8 B E A$ DiBTP- $\mathrm{H}_{2}$}

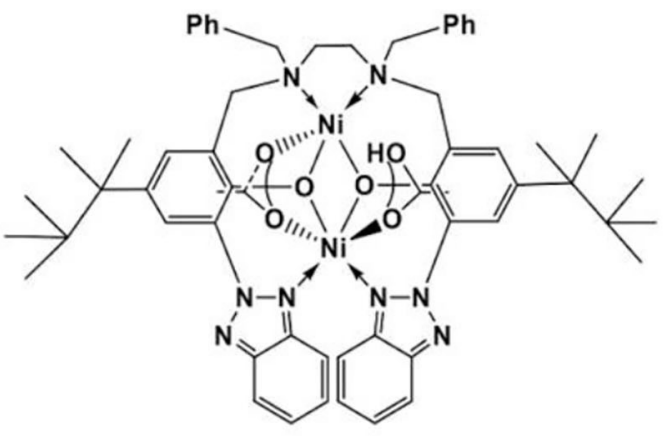

(7)

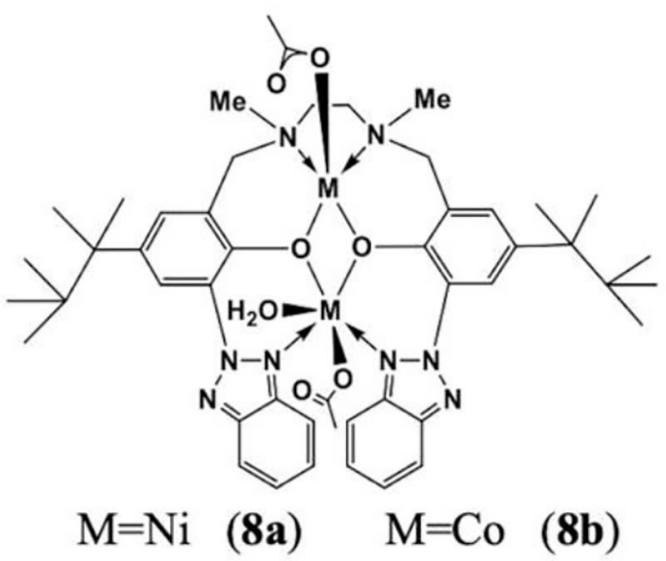

$$
\mathrm{M}_{\mathrm{t}}=\mathrm{Co} \quad(9 \mathrm{a}) \quad \mathrm{M}_{\mathrm{t}}=\mathrm{Ni} \quad(9 \mathrm{~b})
$$

(10)

\section{${ }^{2 C}$ BiIBTP- $\mathrm{H}_{2}$}

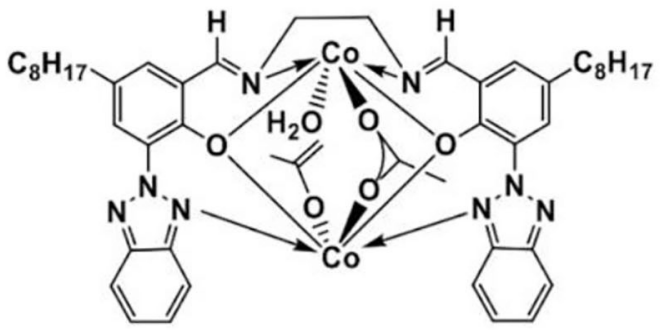

(11)

FIGURE $\mathbf{6}$ | The structures of catalysts $\mathbf{7 - 8}$ or $\mathbf{9 - 1 1}$ based on DiBTP- $\mathrm{H}_{2}$ or BilBTP- $\mathrm{H}_{2}$, respectively.

linkage content (99\%), and polycarbonate selectivity (90\%). After that, in 2020, another type of dinuclear zinc catalysts based on chiral/thioalkoxide NNO-scorpionate ligand was synthesized
(Sobrino et al., 2020). The difference from the previous study is that in catalysts 4-5, the heteroscorpionate ligand is connected to the zinc center through two nitrogen atoms on the pyrazole 
rings, and the oxygen atom on the alkoxy group is connected to the two zinc by $\kappa^{2}-\mathrm{NN} \mu-\mathrm{O}$ coordination mode. In addition, each zinc center is coordinated with an aryloxy ligand (Figure 5, cat. 4-5). In the ROCOP of $\mathrm{CHO}$ and $\mathrm{CO}_{2}$, in the absence of a cocatalyst, catalyst $\mathbf{4}$ shows the best catalytic activity and carbonate selectivity [75\% of conversion, carbonate bond content up to 99\%, and high $\mathrm{PCHC} /$ cyclohexene carbonate (CHC) ratio 93/7].

$\mathrm{Lu}$ and coworkers prepared a series of dinuclear chromium complexes based on bisphenol linking bridge (Figure 5, cat. 6), which can be used for the ROCOP of epoxides [propylene oxide (PO), phenyl glycidyl ether (GO), styrene oxide (SO), 4-chlorostyrene oxide (Cl-SO), epichlorohydrin (ECH), and various meso-epoxides: cyclopentene oxide (CPO), 3,4epoxytetrahydrofuran (COPO), 1,2-epoxy-4-cyclohexene (CEO), cis-2,3-epoxybutane (CBO), and 1,4-dihydro-naphthalene oxide $(\mathrm{CDO})$ ] with cyclic anhydrides [SA, glutaric anhydride (GA), diglycolic anhydride (DGA), PA, and $\mathrm{MA}]$ or $\mathrm{CO}_{2}$ or dihydrocoumarin (DHC), with co-catalysts PPN-X $(\mathrm{X}=\mathrm{Cl}$, $\mathrm{NO}_{3}, \mathrm{~N}_{3}$ ). Besides, these catalyst systems can also be used for the one-pot alternating terpolymerization of $\mathrm{PO} / \mathrm{PA} / \mathrm{CO}_{2}$, $\mathrm{PO} / \mathrm{PA} / \mathrm{DHC}$, or $\mathrm{PO} / \mathrm{CO}_{2} / \mathrm{DHC}$ to prepare polyester- $b$ polycarbonate, polyester- $b$-polyester, or poly(ester-co-carbonate) (Liu et al., 2018). Later, this group developed polyesters with completely alternating structures based on the similar catalyst system and trans-internal epoxides [trans-CSO, $(S, S)$-CSO, and trans-CTO] and cyclic anhydrides (PA, 1,2-NA, 3,4-DMPA, DPA, and GA). All polyesters were stereoirregular, where poly(ractrans-CSO-alt-1,2-NA) and poly(rac-trans-CSO-alt-3,4-DMPA) were amorphous with high $T_{\mathrm{g}}$ values of 197 and $178^{\circ} \mathrm{C}$, respectively, but the poly $[(S, S)$-CSO-alt-1,2-NA $]$ and poly $[(S, S)$ CSO-alt-3,4-DMPA] were semi-crystalline polymers with melting temperatures $\left(T_{\mathrm{m}}\right)$ of 256 and $280^{\circ} \mathrm{C}$, respectively. The poly $[(\mathrm{S}, \mathrm{S})-\mathrm{CSO} / \mathrm{DPA}]$, poly[(S,S)-CSO/GA], and poly[(S,S)$\mathrm{CTO} / \mathrm{PA}]$ were stereoirregular and amorphous. This study also pointed out that the substituents of the cyclic anhydride backbone and the aromatic structure with higher rigidity can significantly improve crystallinity and thermostability (Liu et al., 2019).

The Ko group has proposed a series of multinuclear metal catalysts, for instance, di-nickel (Lin et al., 2016; Tsai et al., 2016; Huang et al., 2017; Li et al., 2019b; Su et al., 2020a,b), di-zinc (Chang et al., 2016), di-cobalt (Su et al., 2019b), and bi-yttrium (Su et al., 2019a), using amine bis(benzotriazole phenolate) and its derivatives as the ligand, for the ROCOP of epoxides with $\mathrm{CO}_{2}$ or cyclic anhydrides (Su et al., 2014; Chuang and Ko, 2015; Yu et al., 2016; Li et al., 2017a; Chang et al., 2018). In 2016, the Ko group reported the heat-resistant metal catalysts, bearing multidentate diaminebis(benzotriazole phenolate) (DiBTP) derivatives (Figure 6, cat. 7-8), which remained active at a temperature of up to $140^{\circ} \mathrm{C}$. 8a showed a better catalytic activity than 7 due to the less sterically encumbered coordination sphere, which promotes the coordination of $\mathrm{CHO}$ monomers or the insertion of $\mathrm{CO}_{2}$ during the copolymerization. 8a can also catalyze the copolymerization of $\mathrm{VCHO}$ with $\mathrm{CO}_{2}$ to produce cross-linkable poly(vinyl cyclohexene carbonate) (Lin et al., 2016). Then this group also synthesized a series of cobalt, nickel, and zinc complexes based on bis(benzotriazolyliminophenolate) (BilBTP) derivatives (Figure 6, cat. 9-11; Yu et al., 2016).

\section{Heterodinuclear Complex Catalyst}

With the development of bimetallic catalysts for ROCOP of epoxides/cyclic anhydrides or $\mathrm{CO}_{2}$, homodinuclear catalysts can produce completely alternating copolymers, but the small scope of ligands and metals limits its development (Trott et al., 2019). Over the last decade, a series of heterodinuclear metallic catalysts have emerged with excellent catalytic performance due to the synergetic effect between metal centers. Detailed kinetic, mechanistic, and theoretical studies suggest a "chain shuttling" mechanism where the rate-limiting step is metalcarbonate attack on a coordinated epoxide; thus, shuttle and activation of monomers at different metal centers can improve catalyst performance (Trott et al., 2019; Deacy et al., 2020a). Moreover, these studies demonstrated that heterodinuclear metal complexes may have better thermodynamic stability than the homodinuclear analogs (Deacy et al., 2018; Trott et al., 2019). This section mainly summarizes the latest progress in the development of heterodinuclear catalysts and their catalytic activity for ROCOP of epoxides and cyclic anhydrides or $\mathrm{CO}_{2}$.

In 2014, the Williams group reported a heterodinuclear $\mathrm{Zn}(\mathrm{II}) / \mathrm{Mg}$ (II) complex based on the macrocyclic ligand (L). For the ROCOP of $\mathrm{CO}_{2}$ and epoxides, the heterodinuclear catalyst showed a much higher catalytic activity $\left(\mathrm{TOF}=79 \mathrm{~h}^{-1}\right)$ than $\mathrm{LZn}_{2}(\mathrm{OAc})_{2}\left(\mathrm{TOF}=17 \mathrm{~h}^{-1}\right)$ or $\mathrm{LMg}_{2}(\mathrm{OAc})_{2}\left(\mathrm{TOF}=52 \mathrm{~h}^{-1}\right)$ or their blends [molar ratio of $\mathrm{LZn}_{2}(\mathrm{OAc})_{2}: \mathrm{LMg}_{2}(\mathrm{OAc})_{2}=$ $\left.1: 1, \mathrm{TOF}=40 \mathrm{~h}^{-1}\right]$. But it is difficult to separate the target product during the preparation of the catalyst (Saini et al., 2014). To address the purification problem, sequential metalation reaction method was used, in which the monometalization of the ligand was first achieved, followed by the addition of the second metal center. In the ROCOP of $\mathrm{CHO}$ with $\mathrm{CO}_{2}$ or PA, the pure $\mathrm{LMgZnBr}_{2}$ (12l) showed the highest catalytic efficiency, compared with the homodinuclear complexes or their mixtures, suggesting a synergetic effect between different metals (Garden et al., 2015).

The type of metal center can significantly affect the polymerization rate, chemoselectivity, molar mass, and structure of the ROCOP polymers. Since the metals from Group 1 or 2 are highly Lewis acidic, considering this feature may enhance the coordination of epoxides, and it is possible to generate unstable metal-carbonate bonds to lead a faster catalytic rate. A series of heterodinuclear combinations, featuring $\mathrm{Zn}$ (II)/M (Deacy et al., 2018, 2020a), were chelated by the macrocyclic ligand (Figure 7). For ROCOP of $\mathrm{CHO} / \mathrm{CO}_{2}$, the most active and selective catalyst feature was $\mathrm{Mg}(\mathrm{II}) / \mathrm{Zn}$ (II), while all other heterodinuclear combinations showed a weaker activity.

In 2019, eight new heterodinuclear metal complexes featuring carboxylate co-ligands were developed, and their catalytic ability for the ROCOP of $\mathrm{CHO} / \mathrm{CO}_{2}$ was investigated (Figure 7, 12m-12t; Trott et al., 2019). Under 1-bar $\mathrm{CO}_{2}$ pressure and 0.1 mol\% catalyst loading, all the heterodinuclear metal complexes were active for the ROCOP at $80^{\circ} \mathrm{C}$, producing polycarbonates 


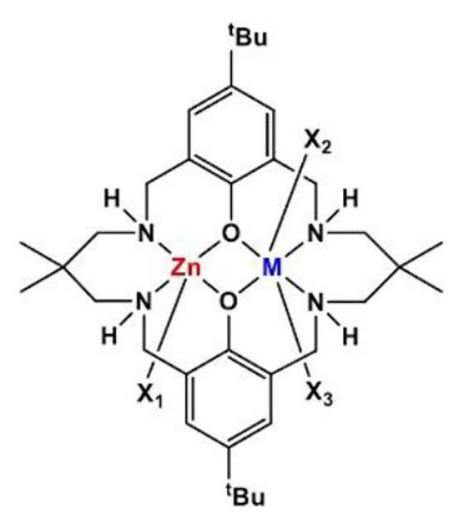

\begin{tabular}{|c|c|c|c|c|c|c|c|c|c|}
\hline M & $\mathbf{X}_{1}$ & $\mathbf{X}_{2}$ & $\mathbf{X}_{3}$ & Cat. & $\mathbf{M}$ & $\mathbf{X}_{1}$ & $\mathbf{X}_{2}$ & $\mathbf{X}_{3}$ & Cat. \\
\hline $\mathrm{Li}$ & none & I & none & $12 a$ & In & $\mathrm{Cl}$ & $\mathrm{Cl}$ & $\mathrm{OOCC}_{6} \mathrm{H}_{5} \mathrm{CF}_{3}$ & $12 k$ \\
\hline $\mathrm{Li}$ & none & $\mathrm{OOCC}_{6} \mathrm{H}_{5} \mathrm{CF}_{3}$ & none & $12 b$ & $\mathrm{Mg}$ & $\mathrm{Br}$ & $\mathrm{Br}$ & none & 121 \\
\hline $\mathrm{Na}$ & none & I & none & $12 \mathrm{c}$ & $\mathrm{Mg}$ & $\mathrm{OOCC}_{6} \mathrm{H}_{6}$ & $\mathrm{OOCC}_{6} \mathrm{H}_{6}$ & none & $12 \mathrm{~m}$ \\
\hline K & none & I & none & $12 d$ & $\mathrm{Mg}$ & $\mathrm{OOCC}_{6} \mathrm{H}_{5} \mathrm{OCH}_{3}$ & $\mathrm{OOCC}_{6} \mathrm{H}_{5} \mathrm{OCH}_{3}$ & none & $12 n$ \\
\hline $\mathrm{K}$ & none & $\mathrm{OOCC}_{6} \mathrm{H}_{5} \mathrm{CF}_{3}$ & none & $12 e$ & $\mathrm{Mg}$ & $\mathrm{OOCC}_{6} \mathrm{H}_{5} \mathrm{CF}_{3}$ & $\mathrm{OOCC}_{6} \mathrm{H}_{5} \mathrm{CF}_{3}$ & none & 120 \\
\hline $\mathrm{Mg}$ & I & I & none & $12 \mathrm{f}$ & $\mathrm{Mg}$ & $\mathrm{OOCC}_{6} \mathrm{H}_{5} \mathrm{NO}_{2}$ & $\mathrm{OOCC}_{6} \mathrm{H}_{5} \mathrm{NO}_{2}$ & none & $12 p$ \\
\hline $\mathrm{Ca}$ & I & I & none & $12 \mathrm{~g}$ & $\mathrm{Mg}$ & $\mathrm{OOCC}_{6} \mathrm{H}_{5} \mathrm{~N}\left(\mathrm{CH}_{3}\right)_{2}$ & $\mathrm{OOCC}_{6} \mathrm{H}_{5} \mathrm{~N}\left(\mathrm{CH}_{3}\right)_{2}$ & none & $12 q$ \\
\hline $\mathrm{Al}$ & $\mathrm{Cl}$ & $\mathrm{Cl}$ & $\mathrm{Cl}$ & $12 \mathrm{~h}$ & $\mathrm{Mg}$ & $\mathrm{OOCC}_{6} \mathrm{H}_{5} \mathrm{~F}$ & $\mathrm{OOCC}_{6} \mathrm{H}_{5} \mathrm{~F}$ & none & $12 r$ \\
\hline $\mathrm{Ca}$ & $\mathrm{Cl}$ & $\mathrm{Cl}$ & $\mathrm{Cl}$ & $12 \mathrm{i}$ & $\mathrm{Mg}$ & $\mathrm{OOCC}_{6} \mathrm{~F}_{5}$ & $\mathrm{OOCC}_{6} \mathrm{~F}_{5}$ & none & $12 \mathrm{~s}$ \\
\hline In & $\mathrm{Cl}$ & $\mathrm{Cl}$ & $\mathrm{Cl}$ & $12 j$ & $\mathrm{Mg}$ & $\mathrm{OOCCH}_{3}$ & $\mathrm{OOCCH}_{3}$ & none & $12 t$ \\
\hline
\end{tabular}

FIGURE 7 | The structures of a series of hetero-Zn/M catalysts based on macrocyclic ligand.

with high carbonate linkage content and exhibited up to $99 \% \mathrm{CO}_{2}$ absorption. Among these complexes, $\mathrm{Zn}(\mathrm{II}) / \mathrm{Mg}(\mathrm{II})$ complex demonstrated the highest catalytic efficiency (TOF $=124 \mathrm{~h}^{-1}$ ), which is significantly higher than the di-Zn(II) $\left(\mathrm{TOF}=18 \mathrm{~h}^{-1}\right.$ ) and di-Mg(II) $\left(\mathrm{TOF}=30 \mathrm{~h}^{-1}\right)$ complexes. Kinetic studies have shown that reaction has a first-order dependence on catalyst and epoxide concentration but a zero-order dependence on $\mathrm{CO}_{2}$ pressure (10-40 bar).

To further investigate the synergetic effect, the difference in catalytic activities between the MgCo heterodinuclear catalysts and the $\mathrm{MgMg}$ and CoCo homodinuclear catalysts was investigated. The synergetic effect was most likely due to the fact that the magnesium center enhances the transition state entropy by reducing the barriers of epoxide coordination, while the cobalt center reduces the transition state enthalpy by enhancing the nucleophilicity of the cobalt carbonate. This study highlights the potential for heterodinuclear synergy and emphasizes the importance of metal selection based on the specific role of metals in the cycle. Further applications of this mechanism can be made with other homodinuclear and heterodinuclear catalysts (Deacy et al., 2020b).

\section{Metal-Free Lewis Pair Catalyst System}

The development of Lewis pair polymerization provides an efficient, controlled, and highly chemoselective approach to ROCOP. Compared with organometallic catalysts, the metal-free Lewis pair catalysts are easy to synthesize and often commercially available (Pappuru and Chakraborty, 2019; Hong, 2021). By adjusting the acidity, basicity, and steric effects, the Lewis acidbase pair can have excellent catalytic performance (Figure 8) (Zhang et al., 2020b). This section only summarizes the very recent highlights.

Chen et al. successfully used a Lewis pair consisting of TEB (as the Lewis acid) and [bis(triphenylphosphine) iminium chloride (PPNCl, as the Lewis base)] for the synthesis of alternating copolymers of $\mathrm{CO}_{2}$ and epoxides, including $\mathrm{PGE}$ and SO. By adjusting the TEB/PPNCl molar ratio, regioregular copolymers can be achieved. They proposed that TEB not only affects the balance of the TEB coordinating anions but also enhances the reaction activity of epoxides. Therefore, excess TEB can reduce the possibility of backbiting reaction. In addition, this study also investigated the catalytic ability of different Lewis pairs comprising TEB 


\section{Lewis acid}<smiles>CCB(CC)CC</smiles>

\section{TEB}

\section{Lewis base}<smiles></smiles>

PPNCl

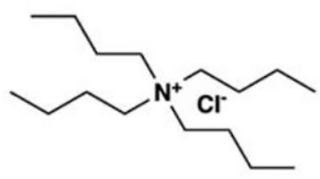

$\mathrm{NBu}_{4} \mathrm{Cl}$<smiles>CN(C)P(=NC(C)(C)C)(N(C)C)N(C)C</smiles>

t-BuP $P_{1}$<smiles>Cl[P-](c1ccccc1)(c1ccccc1)c1ccccc1</smiles><smiles>CN(C)P(=N[PH](N(C)C)(N(C)C)N(C)C)(N(C)C)N(C)C</smiles>

$\mathrm{t}-\mathrm{BuP}_{2}$<smiles>C1CCC2=NCCCN2CC1</smiles>

DBU

FIGURE 8 | Lewis acid and Lewis base in this article.

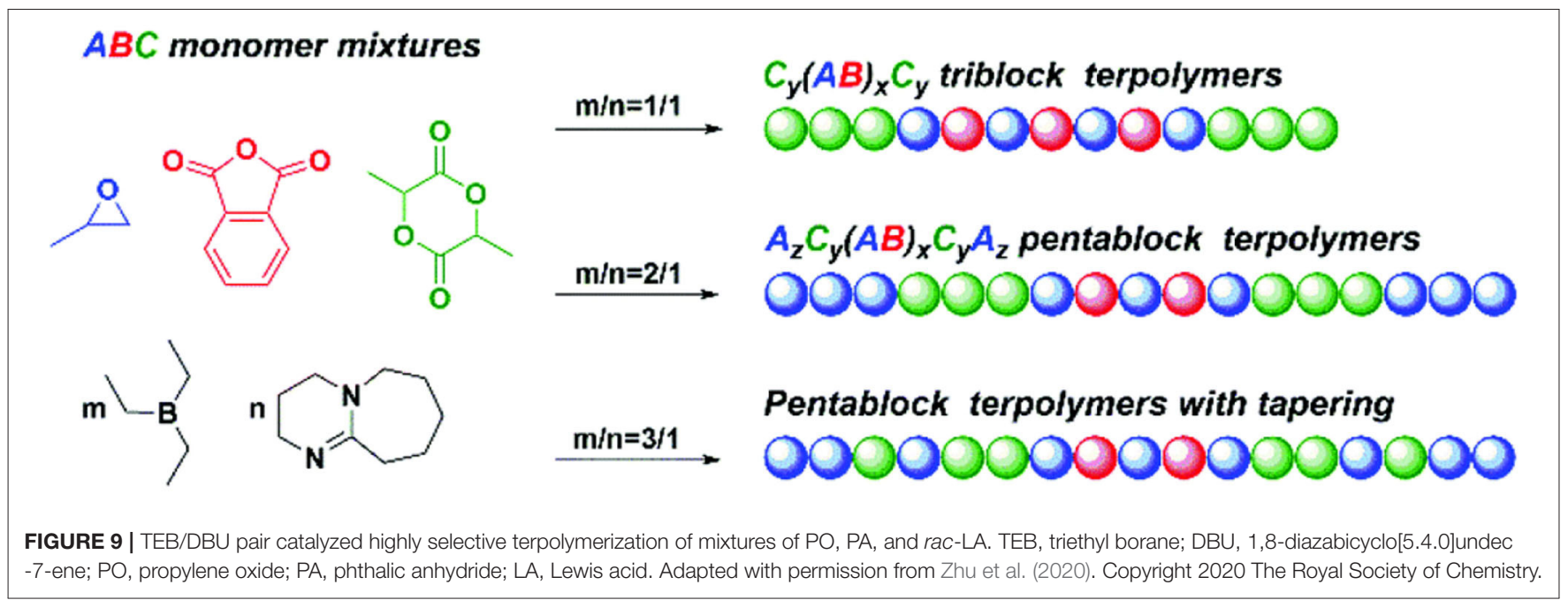

with a series of bases, such as tetrabutylammonium chloride $\left(\mathrm{NBu}_{4} \mathrm{Cl}\right)$, tetraphenylphosphonium chloride $\left(\mathrm{PPh}_{4} \mathrm{Cl}\right), 1,5-$ diazabicyclo[5.4.0] undec-5-ene (DBU), and a phosphazene base $\left(t-\mathrm{BuP}_{2}\right)$, with the molar ratio of $6: 1$. It was found that $\mathrm{NBu}_{4} \mathrm{Cl}$ and $\mathrm{PPh}_{4} \mathrm{Cl}$ showed the lowest catalytic activities (TOFs of 12 and $13 \mathrm{~h}^{-1}$, respectively), where cyclic carbonate was the main product. Meanwhile, the DBU and $t-\mathrm{BuP}_{2}$ with TEB could not catalyze the coupling reaction. In terms of a temperature effect $\left(50 \sim 80^{\circ} \mathrm{C}\right)$ on the ROCOP, it was found that a high reaction temperature would weaken the coordination structure, thus producing more free anions and promoting the backbiting reaction. In addition, the $\mathrm{CO}_{2} / \mathrm{SO}$ copolymers with moderate regional regularity could be obtained by using $\mathrm{TEB} / \mathrm{PPNCl}$ as the catalyst system (Chen et al., 2019).

Similarly, in 2020, Ye et al. used TEB/PPNCl as catalysts to synthesize a tetrameric poly(ester-b-carbonate) copolymer 
A

\section{Initiation}

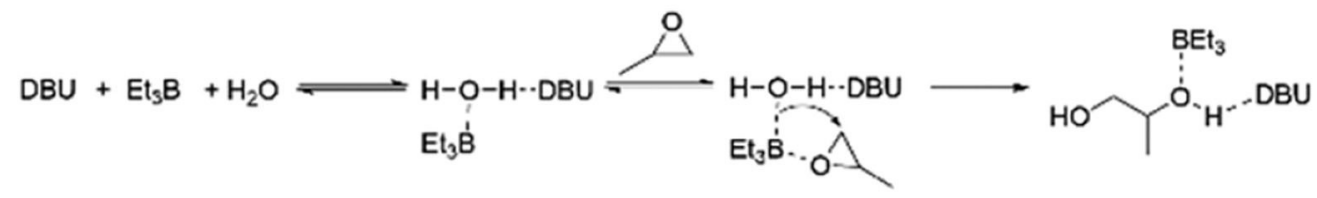

\section{Chain propagation}<smiles>CCCCOC(=O)c1ccccc1C(=O)OC(C)COC(=O)c1ccccc1C(=O)OC(C)CO</smiles><smiles>CCCCOC(C)CO</smiles><smiles>CC1OC(=O)C(C)OC1=O</smiles><smiles>CCCCOC(C)C(=O)OC(C)C(=O)OC(C)CO</smiles><smiles>CCCCC1CC1COC(C)CO</smiles><smiles>CCCCCCC(C)OC(C)CO</smiles>

B

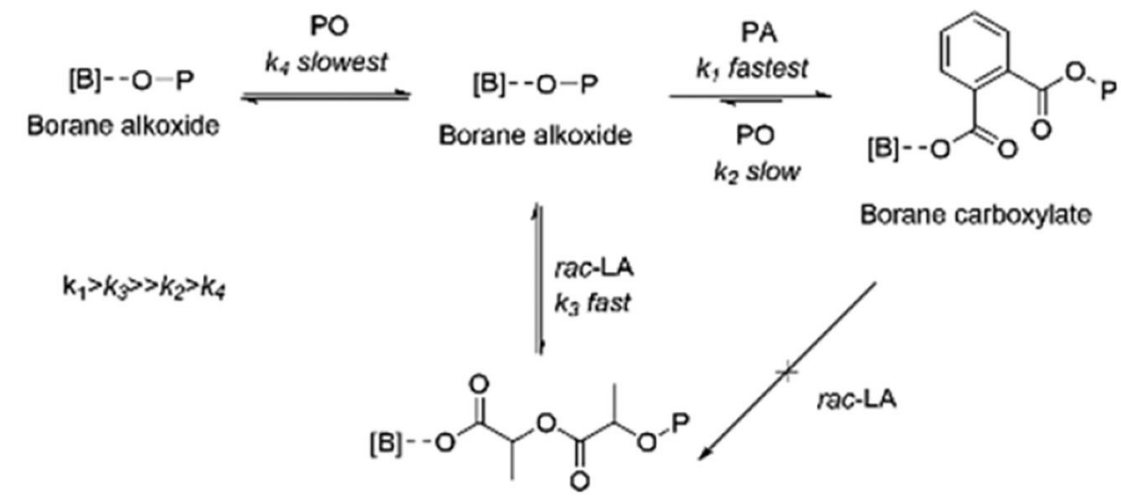

\section{Borane carboxylate}

FIGURE 10 | Plausible mechanistic aspects for the highly selective polymerization process: $\mathrm{H}_{2} \mathrm{O}$-initiated ROCOP and ROP catalyzed by the TEB (Et ${ }_{3} \mathrm{~B}$ )/DBU pair (A) and sequence controlled polymerization from monomer mixtures (B). ROCOP, ring-opening copolymerization; ROP, ring-opening polymerization; TEB, triethyl borane; DBU, 1,8-diazabicyclo[5.4.0]undec-7-ene; LLA-OCA, L-lactide-O-carboxyanhydride. Adapted with permission from Zhu et al. (2020). Copyright 2020 The Royal Society of Chemistry.

using $\mathrm{CO}_{2}, \mathrm{PO}, \mathrm{PA}$, and $\mathrm{CHO}$ as monomers in a one-pot process. The block copolymer showed good biodegradability and a high $T_{\mathrm{g}}$ of $>90^{\circ} \mathrm{C}$. The introduction of $\mathrm{CHO}$ monomer provides rigidity and increases the $T_{\mathrm{g}}$ of the block copolymers. Adjusting monomer feeding ratios allows for controlling $T_{\mathrm{g}}$ values and tuning mechanical properties of the block copolymers. In addition, the block copolymers obtained in this study exhibit good transmittance ( $>85 \%$ ) and high tensile strength (up to 54.8 $\mathrm{MPa}$ ), which could be promising alternatives for conventional non-degradable polystyrene (Ye et al., 2020). Then, Zhang et al. used TEB/PPNCl as the catalysts to synthesize well-defined poly(ester- $b$-carbonate) with unimodal and narrow molecular weight distribution by one-pot and sequential approaches (Zhang et al., 2021).

In 2020, $\mathrm{Zhu}$ et al. used $\mathrm{H}_{2} \mathrm{O}$ as the initiator to catalyze the highly selective ROCOP of PO, PA, and rac-LA with TEB/DBU pair to synthesize $\alpha, \omega$-dihydroxy pentablock terpolymers in one pot (Figure 9; Zhu et al., 2020). First, separate catalytic 

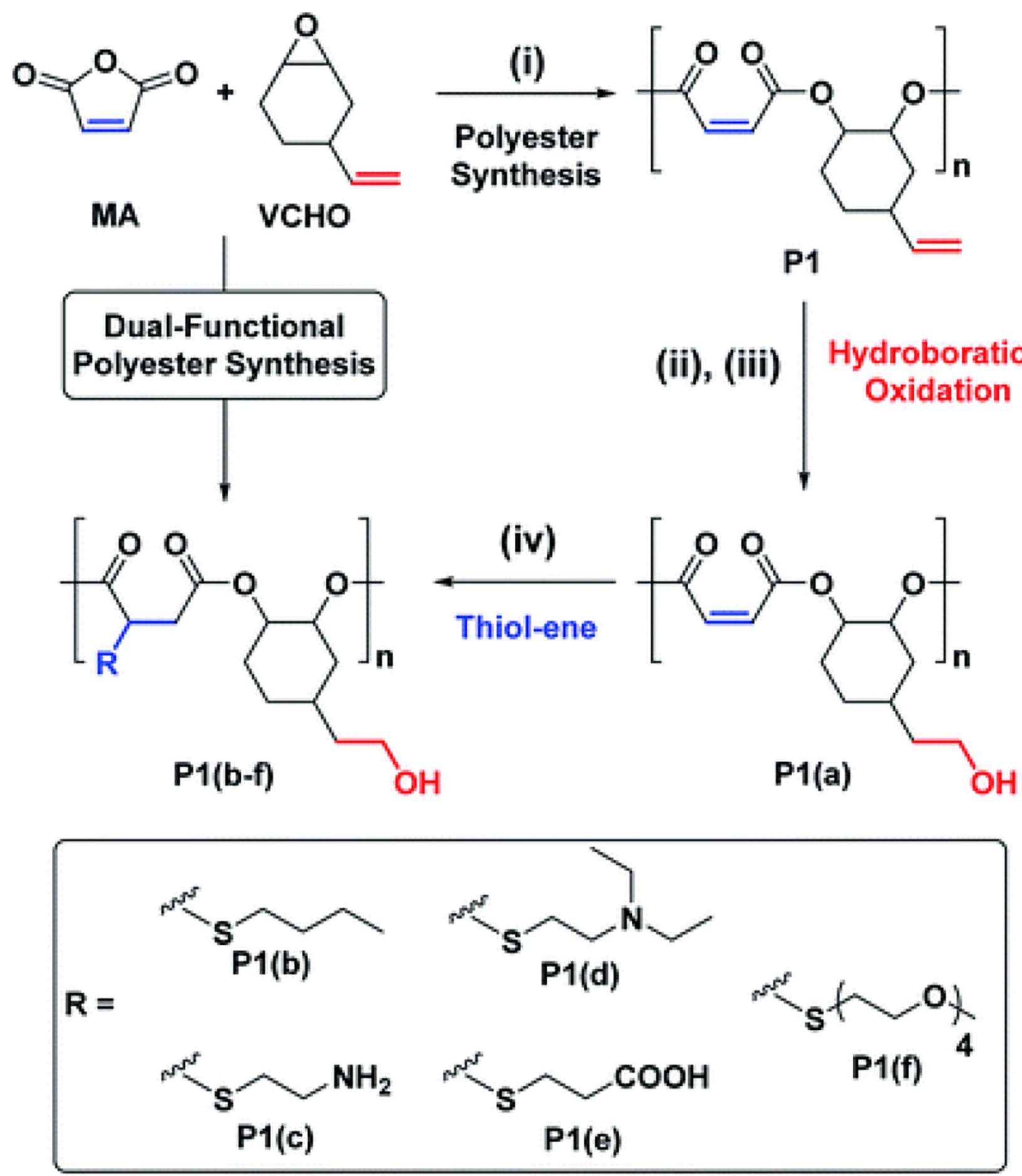

FIGURE 11 | Selective synthesis of dual-functional alternating polyesters (using a combination of MA and VCHO as a representative example). Adapted with permission from Yi et al. (2019). Copyright 2019 The Royal Society of Chemistry.

experiments were carried out, and it was found that with TEB/DBU molar ratio being 1:1, the ROCOP of PO/PA showed a moderate catalytic activity and formed a completely alternating poly(trimethylene phthalate). Although the measured molecular weight was slightly lower than the theoretical value, the polymerization was still well-controlled, showing immortal polymerization features, even with the addition of $\mathrm{H}_{2} \mathrm{O}$, and barely no decrease in the catalytic efficiency was observed. Interestingly, no PO-ROP was observed until the molar ratio of TEB/DBU increased to $2: 1$ and $3: 1$, indicating that additional 


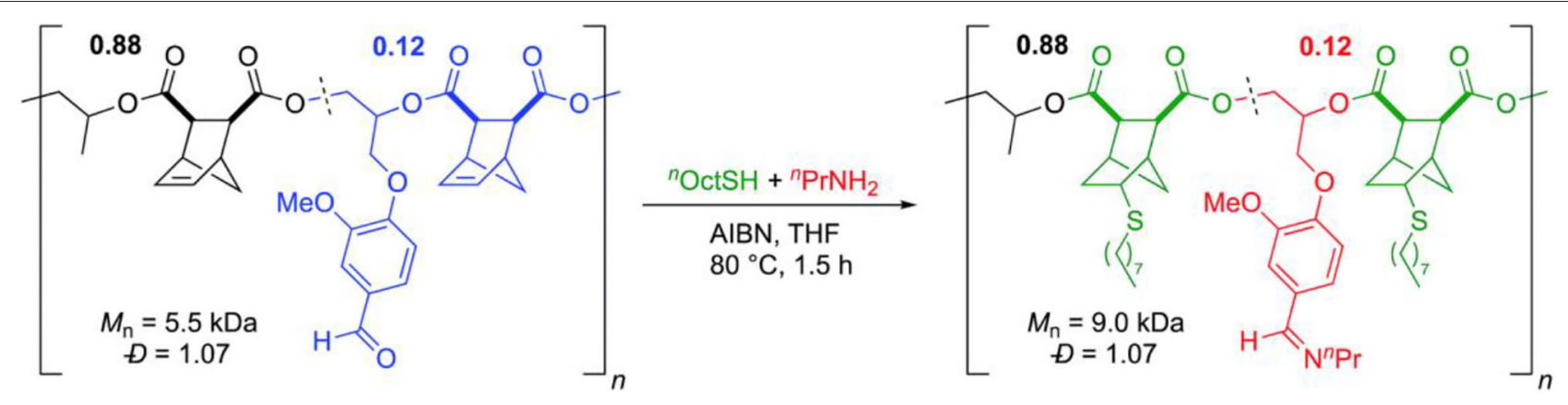

FIGURE 12 | Orthogonal, one-pot, double post-polymerization modification reaction. Adapted with permission from Sanford et al. (2018). Copyright 2018 The Royal Society of Chemistry.

TEB is needed to activate PO in the ROP of PO. Based on these results of separate polymerizations, the ROCOP of $\mathrm{PO} / \mathrm{PA} / \mathrm{rac}$-LA was finally carried out in an autoclave with different TEB/DBU feed ratios using 1 equivalent of $\mathrm{H}_{2} \mathrm{O}$ as the initiator. At $80^{\circ} \mathrm{C}$, the polymerization efficiency was high, and a near complete conversion (>99\%) of $\mathrm{PA}$ and rac-LA was achieved within $5 \mathrm{~h}$. During this terpolymerization, only until the complete consumption of $\mathrm{PA}$ was the ROP of rac-LA able to proceed. In addition, the presence of TEB might also prevent DBU from being an effective transesterification catalyst, so no transesterification occurred even during the extended reaction time. When the molar ratio $\mathrm{TEB} / \mathrm{DBU}$ increased to 2:1 with 3 equivalent of $\mathrm{H}_{2} \mathrm{O}$, the ROCOP of PO/PA, the ROP of rac-LA, and ROP of PO occurred sequentially at $60^{\circ} \mathrm{C}$. However, when increasing the molar ratio to $3: 1$, PO started to homopolymerize even before the complete consumption of rac-LA, resulting in the formation of pentablock copolymers with tapering. This high chemoselectivity could be attributed to the orthogonal catalysis of the borane alkoxide intermediate, resulting from the ring opening of $\mathrm{PO}$ in the presence of water. It connects three polymerization cycles with different monomer insertion rates. The insertion rate of PA into the borane alcohol bond is much faster than that of rac-LA, while the insertion rate of rac-LA is faster than that of PO and highly affected by the molar ratio of TEB/DBU (Figure 10).

\section{POST-POLYMERIZATION MODIFICATION OF POLYMERS OBTAINED BY RING-OPENING COPOLYMERIZATION}

Functional groups such as hydroxyl groups or alkenes on polymer chains can be used as target sites for post-polymerization modification, which can further expand the application potentials of polymers (Farmer et al., 2018). Although the combination of epoxides and $\mathrm{CO}_{2}$ /anhydrides can afford polycarbonates or polyesters by ROCOP, most of the obtained polycarbonates or polyesters lack functionality, restricting their high value-adding applications (Yang et al., 2018). In order to expand the application range of ROCOP polyesters and polycarbonates, epoxides, and anhydrides with different functional groups are of great value. Typical post-polymerization reactions are usually carried out by covalent modifications of the polymer end groups, main chain, and side groups (Gauthier et al., 2009). Among them, thiol-ene click chemistry is the most widely used method (Geschwind et al., 2013; Ntoukam et al., 2020). Besides, the formation of block copolymers or graft copolymers, bearing distinctive block properties (Ghosh et al., 2020; Gregory et al., 2020), could also be a facile approach toward functional materials, such as self-assembled nanomaterials. This section provides an overview of post-polymerization modification for functionalized polycarbonates and polyesters obtained by ROCOP in recent years.

Yi et al. synthesized highly alternating and orthonormal ABtype copolyesters with functional groups of terminal and internal alkenes using different alkene-containing epoxides [VCHO, viny] PO (VPO), or allyl glycidyl ether (AGE)] and anhydrides [MA, tetrahydrophthalic anhydride (THPA), or tricyclic anhydride (TCA)], and SalcyCrCl/PPNCl as catalyst systems (Figure 11). The author first synthesized polyesters by ROCOP; after that, primary hydroxyl groups were introduced to the polyester chain via the selective hydroboration-oxidation reaction of the terminal alkenes. Then the internal alkenes were quantitatively converted into carboxylic acids, amines, alkyl, and oligo-groups groups by thiol-ene reactions. These copolymers with both hydrophobic and hydrophilic blocks can be self-assembled into nanostructures in aqueous solution, which is expected to be used as antimicrobial agents and biodegradable drug delivery vehicles (Yi et al., 2019).

Sanford et al. used vanillin glycidyl ether (VGE) to directly introduce aldehyde functional group into the polymer chain by copolymerizing with $\mathrm{PO}$ and carbic anhydride (CPMA), using the $\left[\left({ }^{\mathrm{F}}\right.\right.$ salph $\left.) \mathrm{Al}(\mathrm{THF})\right][\mathrm{OTf}] /[\mathrm{PPN}]_{2}[\mathrm{ADC}]$ as a bifunctional catalytic system. Then, the poly(VGEalt-CPMA) was treated by orthogonal post-polymerization modification (Figure 12). The aldehyde was reacted with an amine to form an imine linkage, which could be interesting in biomedical applications due to its $\mathrm{pH}$ sensitivity, while the alkene remained unreacted. Analogously, when the alkene was consumed completely through a thiol-ene 


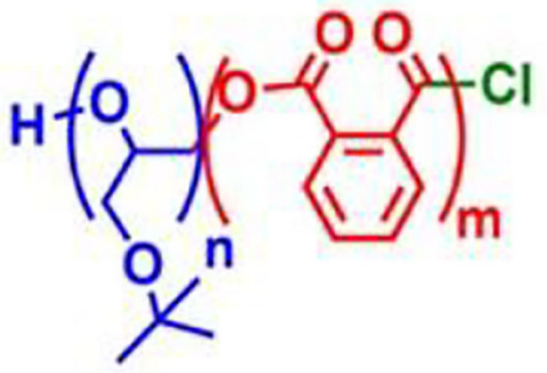

poly(tBGE-alt-PA) copolymer

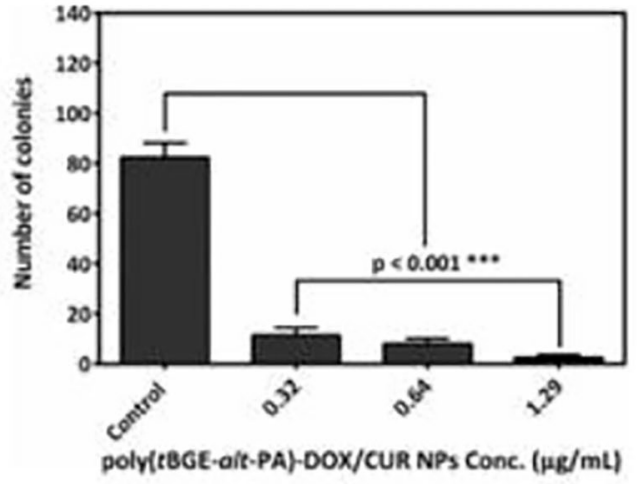

Inhibition of tumor cell growth

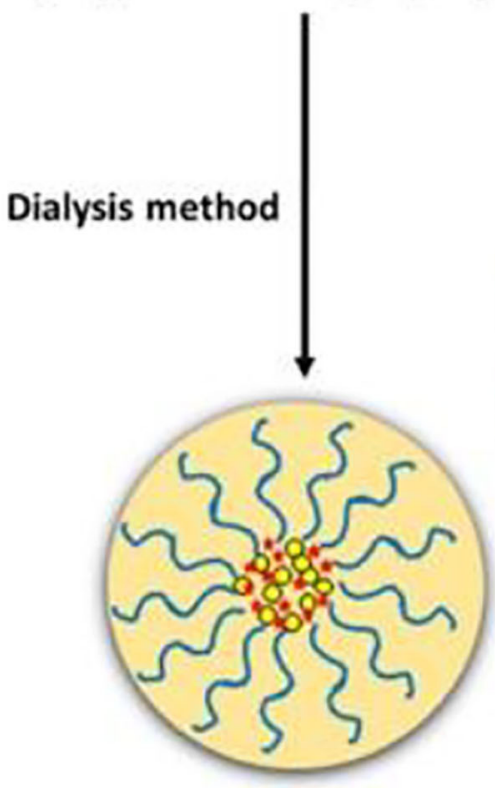

DOX and CUR loaded copolymeric nanoparticles

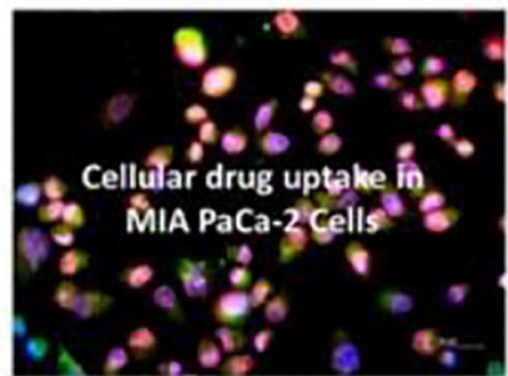

Avg. size $=-200$ to $250 \mathrm{~nm}$

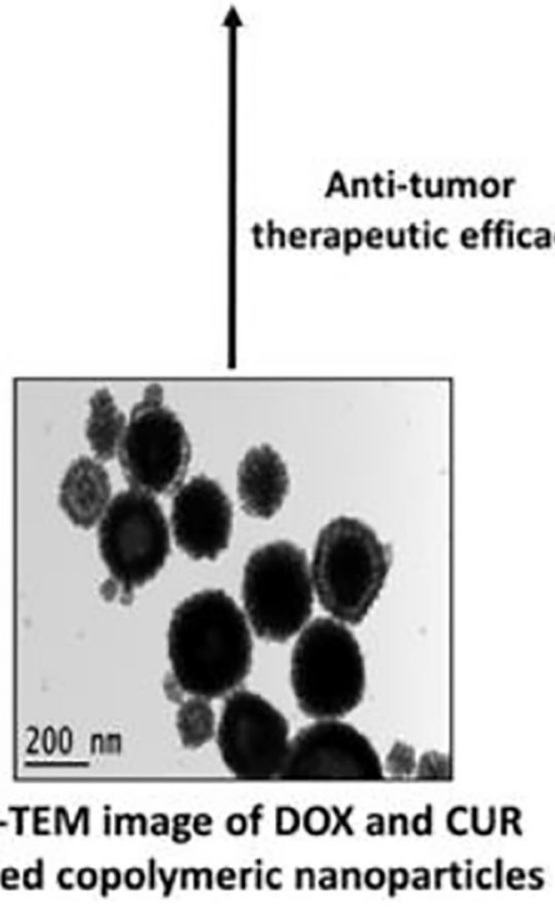

FIGURE 13 | Illustration of doxorubicin (DOX) and curcumin (CUR) loaded nanoparticles self-assembled from poly(tBGE-alt-PA). Adapted with permission from Gupta et al. (2019). Copyright 2019 Elsevier.

reaction, the aldehyde remained intact. One step further, under the same reaction conditions, imine functionalization and thiol-ene reaction were combined into one system, achieving orthogonal and dual post-polymerization modification on aliphatic polyester in one pot (Sanford et al., 2018).

Chang et al. introduced tertiary amine functionalities into poly(PA-alt-VCHO) via the thiol-ene reaction. The wettability property of the obtained polymer showed that the introduction of tertiary amine groups in the polymer chain greatly improved the hydrophilicity of polymer nanofibers, leading to potential biomedical applications (Chang et al., 2018).
In 2014, Darensbourg and coworkers synthesized poly(cyclohexadiene carbonate) by ROCOP of $\mathrm{CO}_{2}$ with 1,2-epoxy-4-cyclohexene, and then they functionalized it by the thiol-ene reaction to afford amphiphilic polymer materials. Thereafter, the polymer was deprotonated with $\mathrm{NH}_{4} \mathrm{OH}$ aqueous solution to afford water-soluble polymers (Darensbourg et al., 2014). Shortly after, they also designed another amphiphilic block copolymer using the (salen)CoTFA/PPNTFA catalyst system. The hydrophobic block PPC was synthesized by the ROCOP of $\mathrm{PO}$ and $\mathrm{CO}_{2}$, and the PAGEC block was prepared by the ROCOP of AGE and $\mathrm{CO}_{2}$. The PAGEC block was then postfunctionalized via the thiol-ene reaction to introduce carboxylic acids on the side chain, leading to the formation of amphiphilic 


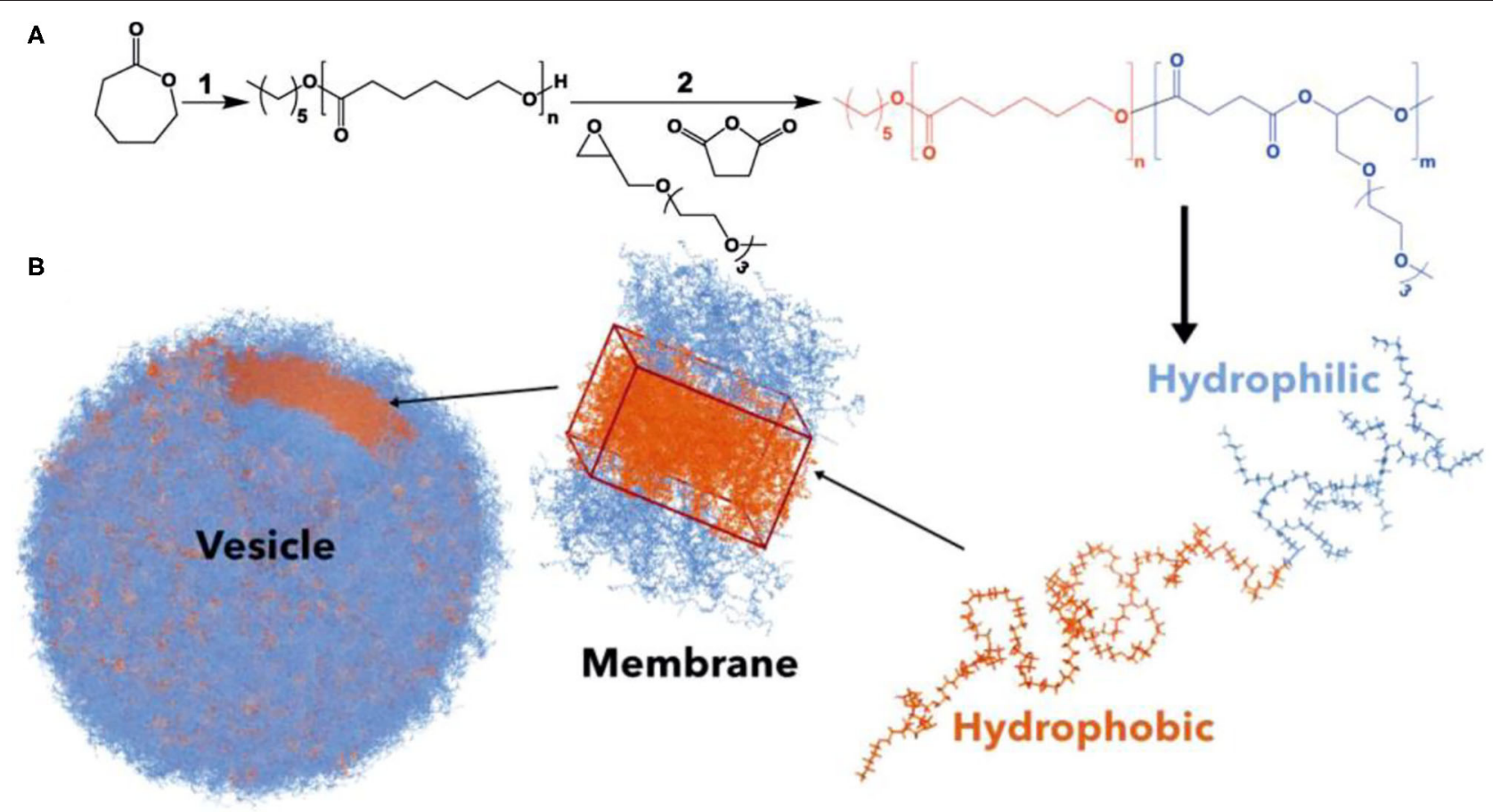

FIGURE 14 | (A) Synthesis of PCL-b-PE. (B) PCL-b-PE forms polymersomes via self-assembly. Adapted with permission from Zhu et al. (2019). Copyright 2019 Wiley.

triblock polycarbonates. The PAGEC- $b$-PPC- $b$-PAGEC can self-assemble into spherical nanoparticles (NPs) with a core-shell morphology in aqueous solution (Wang et al., 2015).

Besides thiol-ene chemistry, Diels-Alder reaction is another facile approach toward post-polymerization modification (Tasdelen, 2011). Hilf et al. prepared a polycarbonate, poly[(furfuryl glycidyl ether)-co-(glycidyl methyl ether)carbonate] poly[(FGE-co-GME)C], using furfuryl glycidyl ether (FGE), glycidyl methyl ether (GME) and $\mathrm{CO}_{2}$ as monomers, and ( $\left.\mathrm{R}, \mathrm{R}\right)-($ salen)-CoCl/PPNCl as the catalyst system (Hilf et al., 2015). The obtained polymer was then reacted with different maleimide derivatives [maleimide, $N$-(methoxycarbonyl) maleimide, and 1-(3,4dihydroxyphenyl)-1H-pyrrol-2,5-dione(dopamine maleimide)] through Diels-Alder reaction to achieve reversible functionality.

\section{POTENTIAL BIOMEDICAL APPLICATIONS OF FUNCTIONAL POLYESTERS AND POLYCARBONATES}

Different from polyesters or polycarbonates prepared by ROP, ROCOP polycarbonates, or polyesters could potentially be more attractive for biomedical applications. As by simply changing the combination of epoxides and anhydrides, the material properties can be easily tuned. However, despite the significant progress made in catalytic systems, the biomedical potentials of the ROCOP polyesters and polycarbonates have not been well-studied, which is most likely due to the fact that ROCOP conditions are usually not compatible with certain functional groups, such as protic groups, and may induce inactivation/denaturation of the incorporated biomolecules (Feng et al., 2012; Dai and Zhang, 2019). Moreover, the organometallic residuals could be cytotoxic, and the degradation behavior of polymers prepared by ROCOP still lacks proper investigation (Xu et al., 2020). In this section, a few pioneering studies of ROCOP polymers for potential biomedical applications will be outlined.

Integrating bio-imaging and drug delivery into one system makes it possible to combine diagnosis and treatment for diseases such as cancer (Wang et al., 2018). Li et al. developed a reliable and effective tumor imaging platform with ROCOP polycarbonates ( $\mathrm{Li}$ et al., 2017b). The triblock polycarbonates, poly(allyl glycidyl ether carbonate)- $b$-poly(propylene carbonate)- $b$-poly(allyl glycidyl ether carbonate) (PAGEC$b$-PPC- $b$-PAGEC), was prepared by sequential epoxide addition during the ROCOP. The obtained triblock polycarbonates were then modified by the thiol-ene reaction between the allyl groups on the PAGEC block and Boc-protected cysteine. Amphiphilicity was achieved after the deprotection of Boc. The amphiphilic triblock polycarbonates were labeled with gadolinium $\left(\mathrm{Gd}^{3+}\right)$ and self-assembled into polymeric micelles, which showed relatively low cytotoxicity both in vitro and in vivo. The polymer micelles were degradable via the hydrolysis of carbonate bonds to release DPTA/Gd complexes. The tumor MRI showed that these Gd-loaded polymer micelles have excellent MR imaging ability. This study demonstrated that $\mathrm{CO}_{2}$-based amphiphilic 

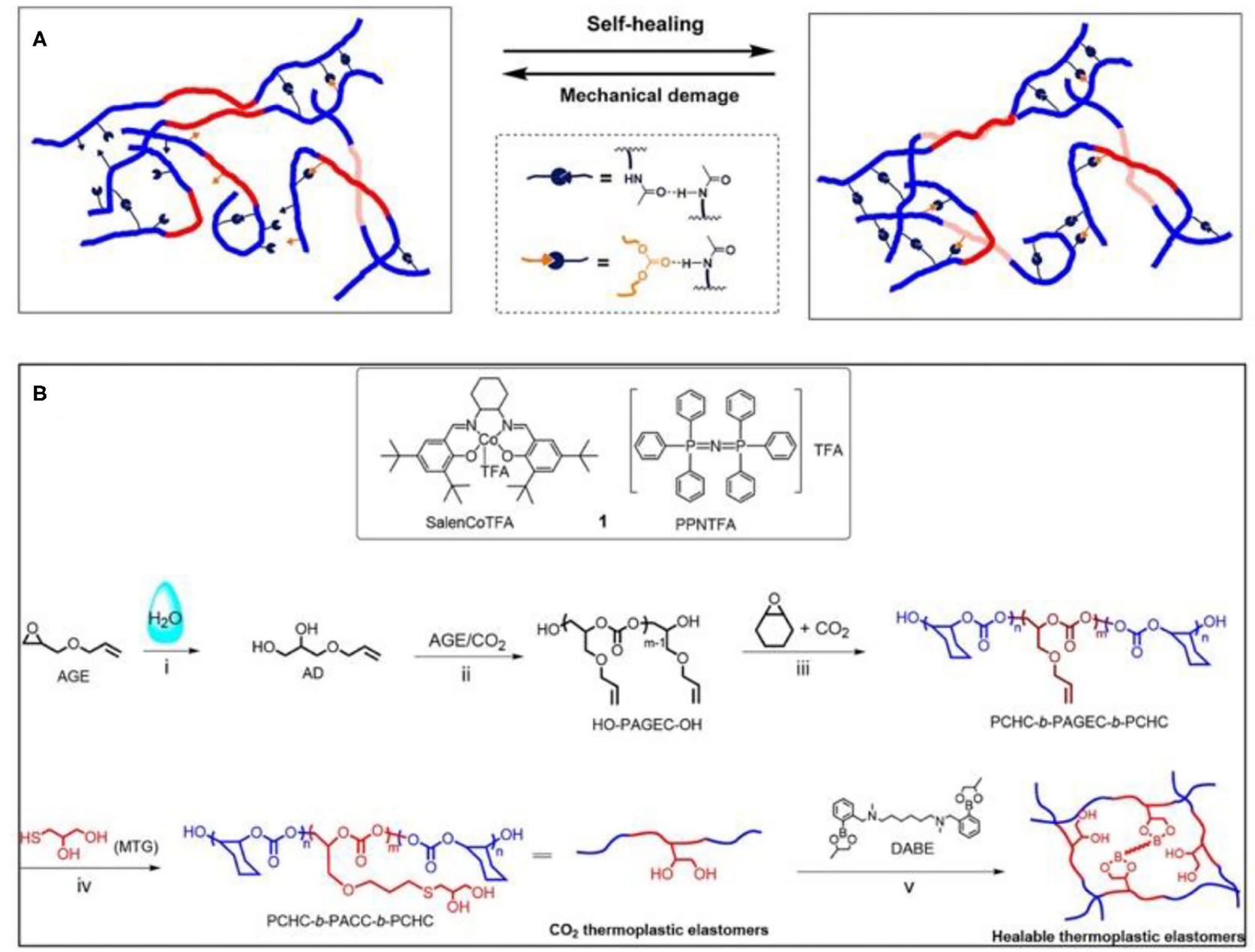

FIGURE 15 | (A) Schematic illustration of the self-healing mechanism of the $\mathrm{CO}_{2}$-based block copolymers (Yang et al., 2018). Adapted with permission from Yang et al. (2018). Copyright 2018 American Chemical Society. (B) SalenCoTFA/PPNTFA catalyst system and tandem strategy performed for the preparation of $\mathrm{CO}_{2}$-based healable thermoplastic elastomers (Yang and Wu, 2019). Adapted with permission from Yang and Wu (2019). Copyright 2019 American Chemical Society.

polycarbonates with improved hydrophilicity and functionality can be used as an efficient platform for tumor imaging (Li et al., 2017b).

Doxorubicin (DOX) and curcumin (CUR) have an antitumor activity; some studies have shown that CUR expresses its chemo-sensitization action by increasing its accumulation in cancer cells to enhance the anti-tumor ability of DOX. Based on this, Gupta et al. prepared different drug-loaded NPs, consisting of poly ( $t$ BGE-alt-PA) with DOX and CUR, and the poly $(t \mathrm{BGE}$-alt-PA) was synthesized with tert-butyl glycidyl ether ( $t \mathrm{BGE}$ ) and PA using the TEB/PPNCl catalyst system (Figure 13). Although poly( $t \mathrm{BGE}$-alt-PA) is biodegradable, TGA results suggested that NPs can be stored for a long time at room temperature. Drug release experiments showed that the in vitro drug release of the NPs followed anomalous transport pattern, with higher cellular drug uptake of DOX and CUR in the NP formulation, compared with free drug. Moreover, drug-loaded NPs had no significant cytotoxicity against MCF-10A cells, and the dual-drug system also showed higher anticancer therapeutic efficacy (Gupta et al., 2019). Kummari et al. tested a few metal-free Lewis pairs on the alternating copolymerization of norbornene anhydride and different epoxides. The obtained polyesters showed good biocompatibility upon human embryonic kidney cells (HEK293) (Kummari et al., 2019).

Zhu et al. demonstrated the significance of polymer degradation products, besides being used simply as delivery vehicles, in metabolic activities to modulate cell behavior. They used PCL as the macroinitiator to initiate the ROCOP of succinic anhydride (SA) and 2-[(2-(2-(2meth-oxyethoxy)ethoxy)ethoxy)methyl]oxirane ( $\left.\mathrm{ME}_{3} \mathrm{MO}\right)$, leading to the formation of amphiphilic PCL- $b$-PE block copolyesters (Figure 14). These polymers formed vesiclelike nanostructures via self-assembly. The self-assembled nanostructure was able to be degraded rapidly by lipase to afford metabolites including succinic acid, 6-hydroxyhexanoic 
acid, and a derivative of glycerol containing tri(ethylene glycol) substituent. These degradation products were found to stimulate the proliferation of dermal fibroblasts, which could be of great value for cell-specific wound healing. This finding signals the importance of designing drug delivery systems with specific metabolic activities (Zhu et al., 2019).

Inspired by the self-healing ability of living organisms, synthetic biomedical self-healing materials have also been extensively studied. Self-healing materials can automatically repair damage to return their original shape, structure, functionality, and physical and chemical properties without external intervention (Chen et al., 2017; Shi et al., 2019). At the molecular level, self-healing methods can be divided into physical events and chemical events (for instance, covalent bonding, free radicals, and supramolecular dynamic bonds; Wang and Urban, 2020). At present, in order to make self-healing materials with good mechanical properties and self-healing ability at the same time, the commonly used method is to prepare multi-block copolymers, in which the hard block provides strength and rigidity for the material and the multivalent supermolecular interactions ensure self-healing (Chen and Guan, 2014; Lee et al., 2020). Darensbourg and Wu's group synthesized a series of $\mathrm{CO}_{2}$-based polycarbonate elastomers with self-healing ability via a one-pot method, combining ROCOP with the thiol-ene reaction as the postpolymerization modification strategy. Triblock copolymer, PAGEC- $b$-PPC- $b$-PAGEC, was prepared first ROCOP. Then, excess $\mathrm{CO}_{2}$ was removed after the consumption of AGE, followed by the addition of 2-amido ethanethiol to perform thiol-ene modification (Figure 15A), introducing self-healing ability (Yang et al., 2018). Due to the reversible hydrogen bonding effect, the obtained polycarbonates showed good self-healing ability and can almost completely recover without any external stimulation at room temperature. Besides, almost no loss of the mechanical properties and self-healing ability were observed even after repetitive thermoforming (Yang et al., 2018). Another healable $\mathrm{CO}_{2}$-based thermoplastic elastomer, PCHC- $b$-PACC- $b$-PCHC, was synthesized via the addition of N1,N6-dimethyl-N1,N6-bis(2-(4-methyl1,3,2-dioxaborolan-2-yl)benzyl)-hexane-1,6-diamine (DABE) as a dynamic cross-linker (Figure 15B). Monothioglycerol was added to perform the thiol-ene click reaction. The experimental results showed that before modification, the block polymer had only one $T_{\mathrm{g}}\left(\sim 20^{\circ} \mathrm{C}\right)$, but after modification, two $T_{\mathrm{g}}$ values $\left(\sim-20\right.$ and $\left.\sim 100^{\circ} \mathrm{C}\right)$ appeared, suggesting the formation of microphase separation and increased hydrophilicity of PACC blocks. The PCHC block offers rigidity, while the dynamic exchange of boronic ester bond ester between the diol groups and telechelic diboronic esters in the soft PACC block/DABE phase contributes self-healing (Yang and $\mathrm{Wu}, 2019$ ).

\section{CONCLUSION AND OUTLOOK}

Compared with other controlled polymerization reactions, ROCOP provides a more facile method to tailor the material properties of polyesters and polycarbonates by simply changing the monomer combinations of epoxides, $\mathrm{CO}_{2}$, and cyclic anhydrides. The catalysis of ROCOP has been investigated for decades, and a few comprehensive reviews have been reported. However, the recent development in multi-nuclear organometallic catalytic systems and metal-free catalytic systems has rarely been summarized. Multi-nuclear organometallic catalysts, especially the heteronuclear ones, generally exhibited higher polymerization rates and polymer selectivities than those of the mononuclear analogs, while the metal-free catalytic system is of great potential to be used for the synthesis of biopolymers. Nevertheless, there are still a few main issues to be addressed, including the lack of understanding of elementary steps during the ROCOP, rigorous polymerization conditions (e.g., high $\mathrm{CO}_{2}$ pressure and high reaction temperature), the lack of stereoselective catalytic systems, and the less well-controlled monomer/block sequence.

In terms of the material properties, though protonic functional groups may not be tolerated during the ROCOP, there are great potentials to introduce functionalities via the post-polymerization modification. The most commonly used approaches are the thiol-ene reaction, hydroborationoxidation reaction, and Diels-Alder reaction. Most importantly, owing to the alternating monomer sequence in ROCOP polymers, orthogonal functionality is easily accessible to reach versatile properties. Such versatility would be a great advantage for biomedical applications, where no single property fits all needs. However, compared with the vast advances in catalysis study, the potential bioapplications of ROCOP polymer have not attracted enough attention. This leaves many opportunities for the future development of ROCOP polymers tailored for biomedicine, including the accurate control of degradation rate to accommodate different application scenarios, understanding the metabolic activity of degradation products, and introducing versatile functionalities with minimum induced toxicity.

\section{AUTHOR CONTRIBUTIONS}

All authors listed have made a substantial, direct and intellectual contribution to the work, and approved it for publication.

\section{FUNDING}

YZ is supported by NSFC (51903190) and the Shanghai Pujiang Program (19PJ1409600). FT is supported by the Fundamental Research Funds for the Central Universities and the Shanghai Pujiang Program (19PJ1408800). 


\section{REFERENCES}

Alferov, K., Wang, S., Li, T., Xiao, M., Guan, S., and Meng, Y. (2019). Co-Ni cyanide bi-metal catalysts: copolymerization of carbon dioxide with propylene oxide and chain transfer agents. Catalysts 8:632. doi: 10.3390/catal9080632

Ambrose, K., Robertson, K. N., and Kozak, C. M. (2019). Cobalt aminobis(phenolate) complexes for coupling and copolymerization of epoxides with carbon dioxide. Dalton Trans. 18, 6248-6260. doi: 10.1039/c9dt00996e

Chang, C. H., Chuang, H. J., Chen, T. Y., Li, C. Y., Lin, C. H., Lee, T. Y., et al. (2016). Di-nuclear zinc complexes containing tridentate imino-benzotriazole phenolate derivatives as efficient catalysts for ring-opening polymerization of cyclic esters and copolymerization of phthalic anhydride with cyclohexene oxide. J. Polym. Sci. A Polym. Chem. 5, 714-725. doi: 10.1002/pola.27902

Chang, C. H., Tsai, C. Y., Lin, W. J., Su, Y. C., Chuang, H. J., Liu, W. L., et al. (2018). Alternating copolymerization of epoxides with carbon dioxide or cyclic anhydrides using bimetallic nickel and cobalt catalysts: preparation of hydrophilic nanofibers from functionalized polyesters. Polymer 141, 1-11. doi: 10.1016/j.polymer.2018.02.063

Chapman, A. M., Keyworth, C., Kember, M. R., Lennox, A. J. J., and Williams, C. K. (2015). Adding value to power station captured $\mathrm{CO}_{2}$ : tolerant $\mathrm{Zn}$ and $\mathrm{Mg}$ homogeneous catalysts for polycarbonate polyol production. ACS Catal. 3 , 1581-1588. doi: $10.1021 / \mathrm{cs} 501798 \mathrm{~s}$

Chen, J., Huang, Y., Ma, X., and Lei, Y. (2017). Functional self-healing materials and their potential applications in biomedical engineering. Adv. Compos. Hybrid Mater. 1, 94-113. doi: 10.1007/s42114-017-0009-y

Chen, Y., and Guan, Z. (2014). Multivalent hydrogen bonding block copolymers self-assemble into strong and tough self-healing materials. Chem. Commun. 74, 10868-10870. doi: 10.1039/c4cc03168g

Chen, Z., Yang, J. L., Lu, X. Y., Hu, L. F., Cao, X. H., Wu, G. P., et al. (2019). Triethyl borane-regulated selective production of polycarbonates and cyclic carbonates for the coupling reaction of $\mathrm{CO}_{2}$ with epoxides. Polym. Chem. 26, 3621-3628. doi: $10.1039 / \mathrm{c} 9 \mathrm{py} 00398 \mathrm{c}$

Cheng, F. Y., Tsai, C. Y., Huang, B. H., Lu, K. Y., Lin, C. C., and Ko, B. T. (2019). Mono- and dinuclear copper complexes coordinated on NNOtridentate Schiff-base derivatives for copolymerization of cyclohexene oxide and cyclic anhydrides. Dalton Trans. 14, 4667-4676. doi: 10.1039/c9dt00471h

Chuang, H. J., and Ko, B. T. (2015). Facilely synthesized benzotriazole phenolate zirconium complexes as versatile catalysts for copolymerization of carbon dioxide with cyclohexene oxide and lactide polymerization. Dalton Trans. 2, 598-607. doi: 10.1039/c4dt02774d

Cui, S., Borgemenke, J., Qin, Y., Liu, Z., and Li, Y. (2019). "Bio-based polycarbonates from renewable feedstocks and carbon dioxide," in Advances in Bioenergy, Vol. 4, eds Y. B. Li and X. M. Ge (Amsterdam: Elsevier), 183-208. doi: $10.1016 /$ bs.aibe.201

Dai, Y., and Zhang, X. (2019). Cationic polycarbonates via ring-opening polymerization: design, synthesis, and applications. Polym. Chem. 10, 296-305. doi: 10.1039/C8PY01365A

Darensbourg, D. J., Chung, W. C., Arp, C. J., Tsai, F. T., and Kyran, S. J. (2014). Copolymerization and cycloaddition products derived from coupling reactions of 1,2-epoxy-4-cyclohexene and carbon dioxide. Postpolymerization functionalization via thiol-ene click reactions. Macromolecules 21, 7347-7353. doi: $10.1021 / \mathrm{ma} 501781 \mathrm{k}$

de la Cruz-Martinez, F., Martinez de Sarasa Buchaca, M., Martinez, J., Tejeda, J., Fernandez-Baeza, J., Alonso-Moreno, C., et al. (2020). Bimetallic zinc catalysts for ring-opening copolymerization processes. Inorg. Chem. 12, 8412-8423. doi: 10.1021/acs.inorgchem.0c00835

Deacy, A. C., Durr, C. B., Garden, J. A., White, A. J. P., and Williams, C. K. (2018). Groups 1,2 and $\mathrm{Zn}(\mathrm{II})$ heterodinuclear catalysts for epoxide/ $\mathrm{CO}_{2}$ ring-opening copolymerization. Inorg. Chem. 24, 15575-15583. doi: 10.1021/acs.inorgchem.8b02923

Deacy, A. C., Durr, C. B., and Williams, C. K. (2020a). Heterodinuclear complexes featuring $\mathrm{Zn}$ (ii) and $\mathrm{M}=\mathrm{Al}($ iii), $\mathrm{Ga}$ (iii) or $\mathrm{In}($ iii) for cyclohexene oxide and $\mathrm{CO}_{2}$ copolymerisation. Dalton Trans. 1, 223-231. doi: 10.1039/ c9dt02918d

Deacy, A. C., Kilpatrick, A. F. R., Regoutz, A., and Williams, C. K. (2020b). Understanding metal synergy in heterodinuclear catalysts for the copolymerization of $\mathrm{CO}_{2}$ and epoxides. Nat. Chem. 4, 372-380. doi: $10.1038 / \mathrm{s} 41557-020-0450-3$
Denk, A., Kernbichl, S., Schaffer, A., Kränzlein, M., Pehl, T., and Rieger, B. (2020). Heteronuclear, monomer-selective $\mathrm{Zn} / \mathrm{Y}$ catalyst combines copolymerization of epoxides and $\mathrm{CO}_{2}$ with group-transfer polymerization of Michael-type monomers. ACS Macro Lett. 4, 571-575. doi: 10.1021/acsmacrolett.9b01025

Farmer, T. J., Comerford, J. W., Pellis, A., and Robert, T. (2018). Postpolymerization modification of bio-based polymers: maximizing the high functionality of polymers derived from biomass. Polym. Int. 67, 775-789. https://doi.org/10.1002/pi.5573 doi: 10.1002/pi.5573

Feng, J., Zhuo, R. X., and Zhan, X. Z. (2012). Construction of functional aliphatic polycarbonates for biomedical applications. Prog. Polym. Sci. 37, 211-236. doi: $10.1016 /$ j.progpolymsci.2011.07.008

Garden, J. A., Saini, P. K., and Williams, C. K. (2015). Greater than the sum of its parts: a heterodinuclear polymerization catalyst. J. Am. Chem. Soc. 48, 15078-15081. doi: 10.1021/jacs.5b09913

Garden, J. A., White, A. J. P., and Williams, C. K. (2017). Heterodinuclear titanium/zinc catalysis: synthesis, characterization and activity for $\mathrm{CO}_{2}$ /epoxide copolymerization and cyclic ester polymerization. Dalton Trans. 8, 2532-2541. doi: 10.1039/c6dt04193k

Gauthier, M. A., Gibson, M. I., and Klok, H. A. (2009). Synthesis of functional polymers by post-polymerization modification. Angew. Chem. Int. Ed. 48, 48-58. doi: 10.1002/anie.200801951

Geschwind, J., Wurm, F., and Frey, H. (2013). From $\mathrm{CO}_{2}$-based multifunctional polycarbonates with a controlled number of functional groups to graft polymers. Macromol. Chem. Phys. 8, 892-901. doi: 10.1002/macp.201200608

Ghosh, S., Glöckler, E., Wölper, C., Tjaberings, A., Gröschel, A. H., and Schulz, S. (2020). Active Ga-catalysts for the ring opening homo- and copolymerization of cyclic esters, and copolymerization of epoxide and anhydrides. Dalton Trans. 38, 13475-13486. doi: 10.1039/d0dt02831b

Gregory, G. L., Sulley, G. S., Carrodeguas, L. P., Chen, T. T. D., Santmarti, A., Terrill, N. J., et al. (2020). Triblock polyester thermoplastic elastomers with semi-aromatic polymer end blocks by ring-opening copolymerization. Chem. Sci. 25, 6567-6581. doi: 10.1039/d0sc00463d

Gupta, P. K., Pappuru, S., Gupta, S., Patra, B., Chakraborty, D., and Verma, R. S. (2019). Self-assembled dual-drug loaded core-shell nanoparticles based on metal-free fully alternating polyester for cancer theranostics. Mater. Sci. Eng. C Mater. Bio. Appl. 101, 448-463. doi: 10.1016/j.msec.2019.03.041

Hilf, J., Scharfenberg, M., Poon, J., Moers, C., and Frey, H. (2015). Aliphatic polycarbonates based on carbon dioxide, furfuryl glycidyl ether, and glycidyl methyl ether: reversible functionalization and cross-linking. Macromol. Rapid Commun. 2, 174-179. doi: 10.1002/marc.201400504

Hong, M. (2021). "Lewis acid-base pairs for polymerization catalysis: recent progress and perspectives," in Frustrated Lewis Pairs. Molecular Catalysis, Vol. 2, eds J. Chris Slootweg and A. R. Jupp (Cham: Springer), 283-317.

Huang, L. S., Tsai, C. Y., Chuang, H. J., and Ko, B. T. (2017). Copolymerization of carbon dioxide with epoxides catalyzed by structurally well-characterized dinickel bis(benzotriazole iminophenolate) complexes: influence of carboxylate ligands on the catalytic performance. Inorg. Chem. 11, 6141-6151. doi: 10.1021/acs.inorgchem.7b00090

Jeske, R. C., Rowley, J. M., and Coates, G. W. (2008). Pre-rate-determining selectivity in the terpolymerization of epoxides, cyclic anhydrides, and $\mathrm{CO}_{2}$ : a one-step route to diblock copolymers. Angew. Chem. Int. Ed. 32, 6041-6044. doi: $10.1002 /$ anie. 200801415

Ji, H. Y., Chen, X. L., Wang, B., Pan, L., and Li, Y. S. (2018a). Metalfree, regioselective and stereoregular alternating copolymerization of monosubstituted epoxides and tricyclic anhydrides. Green Chem. 17, 3963-3973. doi: 10.1039/c8gc01641k

Ji, H. Y., Song, D. P., Wang, B., Pan, L., and Li, Y. S. (2019). Organic Lewis pairs for selective copolymerization of epoxides with anhydrides to access sequence-controlled block copolymers. Green Chem. 22, 6123-6132. doi: $10.1039 / \mathrm{c} 9 \mathrm{gc} 02429 \mathrm{~h}$

Ji, H. Y., Wang, B., Pan, L., and Li, Y. S. (2018b). One-step access to sequence-controlled block copolymers by self-switchable organocatalytic multicomponent polymerization. Angew. Chem. Int. Ed. 51, 16888-16892. doi: $10.1002 /$ anie.201810083

Kember, M. R., and Williams, C. K. (2012). Efficient magnesium catalysts for the copolymerization of epoxides and $\mathrm{CO}_{2}$; using water to synthesize polycarbonate polyols. J Am Chem Soc. 134, 15676-15679. doi: $10.1021 / \mathrm{ja} 307096 \mathrm{~m}$ 
Kummari, A., Pappuru, S., Gupta, P. K., Chakraborty, D., and Verma, R. S. (2019). Metal-free Lewis pair catalyst synergy for fully alternating copolymerization of norbornene anhydride and epoxides: biocompatible tests for derived polymers. Mater Today Commun. 19, 306-314. doi: 10.1016/j.mtcomm.2019.02.007

Lee, H. M., Perumal, S., Kim, G. Y., Kim, J. C., Kim, Y. R., Kim, M. P., et al. (2020). Enhanced thermomechanical property of a self-healing polymer via self-assembly of a reversibly cross-linkable block copolymer. Polym. Chem. 22, 3701-3708. doi: 10.1039/d0py00310g

Li, C. Y., Su, Y. C., Lin, C. H., Huang, H. Y., Tsai, C. Y., Lee, T. Y., et al. (2017a). Synthesis and characterization of trimetallic cobalt, zinc and nickel complexes containing amine-bis(benzotriazole phenolate) ligands: efficient catalysts for coupling of carbon dioxide with epoxides. Dalton Trans. 44, 15399-15406. doi: $10.1039 / \mathrm{c} 7 \mathrm{dt} 02841 \mathrm{e}$

Li, H., He, G., Chen, Y., Zhao, J., and Zhang, G. (2019a). One-step approach to polyester-polyether block copolymers using highly tunable bicomponent catalyst. ACS Macro Lett. 8, 973-978. doi: 10.1021/acsmacrolett.9b00439

Li, M. H., Liu, G. L., Su, Y. C., and Ko, B. T. (2019b). Nickel-catalyzed copolymerization of carbon dioxide with internal epoxides by di-nuclear bis(benzotriazole iminophenolate) complexes. Eur. Polym. J. 120, 109224. doi: 10.1016/j.eurpolymj.2019.109224

Li, Y., Liu, S., Zhao, X., Wang, Y., Liu, J., Wang, X., et al. (2017b). $\mathrm{CO}_{2}$-based amphiphilic polycarbonate micelles enable a reliable and efficient platform for tumor imaging. Theranostics, 19. doi: 10.7150/thno.21672

Liang, J., Ye, S., Wang, S., Xiao, M., and Meng, Y. (2021). Design and structure of catalysts: syntheses of carbon dioxide-based copolymers with cyclic anhydrides and/or cyclic esters. Polym J. 53, 3-27. doi: 10.1038/s41428-020-0374-1

Lin, L., Liang, J., Xu, Y., Wang, S., Xiao, M., Sun, L., et al. (2019). Fully alternating sustainable polyesters from epoxides and cyclic anhydrides: economical and metal-free dual catalysis. Green Chem. 21, 2469-2477. doi: $10.1039 / C 9 G C 00432 \mathrm{G}$

Lin, P. M., Chang, C. H., Chuang, H. J., Liu, C. T., Ko, B. T., and Lin, C. C. (2016). Bimetallic nickel complexes that bear diamine-bis(benzotriazole phenolate) derivatives as efficient catalysts for the copolymerization of carbon dioxide with epoxides. Chem CatChem. 5, 984-991. doi: 10.1002/cctc.201501280

Liu, F. P., Li, J., Liu, Y., Ren, W. M., and Lu, X. B. (2019). Alternating copolymerization of trans-internal epoxides and cyclic anhydrides mediated by dinuclear chromium catalyst systems. Macromolecules 15, 5652-5657. doi: 10.1021/acs.macromol.9b00989

Liu, Y., Guo, J. Z., Lu, H. W., Wang, H. B., and Lu, X. B. (2018). Making various degradable polymers from epoxides using a versatile dinuclear chromium catalyst. Macromolecules 3, 771-778. doi: 10.1021/acs.macromol.7b02042

Longo, J. M., Sanford, M. J., and Coates, G. W. (2016). Ring-opening copolymerization of epoxides and cyclic anhydrides with discrete metal complexes: structure-property relationships. Chem. Rev. 116:15167-15197. doi: 10.1021/acs.chemrev.6b00553

Martínez, J., Castro-Osma, J. A., Lara-Sánchez, A., Otero, A., Fernández-Baeza, J., Tejeda, J., et al. (2016). Ring-opening copolymerisation of cyclohexene oxide and carbon dioxide catalysed by scorpionate zinc complexes. Polym. Chem. 7, 6475-6484. doi: 10.1039/c6py01559j

McGraw, M. L., and Chen, E. Y. X. (2020). Lewis pair polymerization: perspective on a ten-year journey. Macromolecules 15, 6102-6122. doi: 10.1021/acs.macromol.0c01156

Nachtergael, A., Coulembier, O., Dubois, P., Helvenstein, M., Duez, P., Blankert, B., et al. (2015). Organocatalysis paradigm revisited: are metal-free catalysts really harmless? Biomacromolecules 2, 507-514. doi: 10.1021/bm5015443

Ntoukam, D. H. S., Mutlu, H., and Theato, P. (2020). Post-polymerization modification of poly(vinylcyclopropanes): a potential route to periodic copolymers. Eur. Polym. J. 122:109319. doi: 10.1016/j.eurpolymj.2019.109319

Pappuru, S., and Chakraborty, D. (2019). Progress in metal-free cooperative catalysis for the ring-opening copolymerization of cyclic anhydrides and epoxides. Eur. Polym. J. 121:109276. doi: 10.1016/j.eurpolymj.2019.109276

Paul, S., Romain, C., Shaw, J., and Williams, C. K. (2015a). Sequence selective polymerization catalysis: a new route to ABA block copoly(ester-b-carbonateb-ester). Macromolecules 17, 6047-6056. doi: 10.1021/acs.macromol.5b01293

Paul, S., Zhu, Y., Romain, C., Brooks, R., Saini, P. K., and Williams, C. K. (2015b). Ring-opening copolymerization (ROCOP): synthesis and properties of polyesters and polycarbonates. Chem. Commun. 30, 6459-6479. doi: $10.1039 / \mathrm{c} 4 \mathrm{cc} 10113 \mathrm{~h}$
Raman, S. K., Raja, R., Arnold, P. L., Davidson, M. G., and Williams, C. K. (2019). Waste not, want not: $\mathrm{CO}_{2}$ (re)cycling into block polymers. Chem. Commun. 51, 7315-7318. doi: 10.1039/c9cc02459j

Romain, C., Garden, J. A., Trott, G., Buchard, A., White, A. J. P., and Williams, C. K. (2017). Di-zinc-aryl complexes: $\mathrm{CO}_{2}$ insertions and applications in polymerisation catalysis. Chem. Eur. J. 30, 7367-7376. doi: 10.1002/chem.201701013

Romain, C., Zhu, Y., Dingwall, P., Paul, S., Rzepa, H. S., Buchard, A., et al. (2016). Chemoselective polymerizations from mixtures of epoxide, lactone, anhydride, and carbon dioxide. J. Am. Chem. Soc. 12, 4120-4131. doi: 10.1021/jacs. $5 b 13070$

Romain, D. C., and Williams, C. K. (2014). Chemoselective polymerization control: from mixed-monomer feedstock to copolymers. Angew. Chem. Int. Ed. 6, 1607-1610. doi: 10.1002/anie.201309575

Saini, P. K., Fiorani, G., Mathers, R. T., and Williams, C. K. (2017). Zinc versus magnesium: orthogonal catalyst reactivity in selective polymerizations of epoxides, bio-derived anhydrides and carbon dioxide. Chem. Eur. J. 18, 4260-4265. doi: 10.1002/chem.201605690

Saini, P. K., Romain, C., and Williams, C. K. (2014). Dinuclear metal catalysts: improved performanceof heterodinuclear mixed catalysts for $\mathrm{CO}_{2}-$ epoxide copolymerization. Chem. Commun. 32, 4146-4167. doi: 10.1039/ c3cc49158g

Sanford, M. J., Van Zee, N. J., and Coates, G. W. (2018). Reversible-deactivation anionic alternating ring-opening copolymerization of epoxides and cyclic anhydrides: access to orthogonally functionalizable multiblock aliphatic polyesters. Chem. Sci. 1, 134-142. doi: 10.1039/c7sc03643d

Shi, L., Ding, P., Wang, Y., Zhang, Y., Ossipov, D., and Hilborn, J. (2019). Selfhealing polymeric hydrogel formed by metal-ligand coordination assembly: design, fabrication, and biomedical applications. Macromol. Rapid Commun. 7:e1800837. doi: 10.1002/marc.201800837

Sobrino, S., Navarro, M., Fernández-Baeza, J., Sánchez-Barba, L. F., Lara-Sánchez, A., Garcés, A., et al. (2020). Efficient production of poly(cyclohexene carbonate) via ROCOP of cyclohexene oxide and $\mathrm{CO}_{2}$ mediated by NNO-scorpionate zinc complexes. Polymers 9:2148. doi: 10.3390/polym12092148

Stadler, B. M., Wulf, C., Werner, T., Tin, S., and de Vries, J. G. (2019). Catalytic approaches to monomers for polymers based on renewables. ACS Catal. 9, 8012-8067. doi: 10.1021/acscatal.9b01665

Su, C. K., Chuang, H. J., Li, C. Y., Yu, C. Y., Ko, B. T., Chen, J. D., et al. (2014). Oxo-bridged bimetallic Group 4 complexes bearing amine-bis(benzotriazole phenolate) derivatives as bifunctional catalysts for ring-opening polymerization of lactide and copolymerization of carbon dioxide with cyclohexene oxide. Organometallics 24, 7091-7100. doi: 10.1021/om500784a

$\mathrm{Su}$, Y. C., Chen, C. T., and Ko, B. T. (2020a). Catalysis and kinetics for alternating copolymerization of carbon dioxide with epoxides using dinuclear nickel catalysts of pyrazolyl based diamine-bisphenolate ligands. Polymer 200:122553. doi: 10.1016/j.polymer.2020.122553

Su, Y. C., Liu, W. L., Li, C. Y., and Ko, B. T. (2019a). Air-stable dinuclear yttrium complexes as versatile catalysts for lactide polymerization and copolymerization of epoxides with carbon dioxide or phthalic anhydride. Polymer 167, 21-30. doi: 10.1016/j.polymer.2019.01.060

Su, Y. C., Tsai, C. Y., Huang, L. S., Lin, C. H., and Ko, B. T. (2019b). Synthesis and characterization of di-nuclear bis(benzotriazole iminophenolate) cobalt complexes: catalysis for the copolymerization of carbon dioxide with epoxides. Dalton Trans. 32, 12239-12249. doi: 10.1039/c9dt02174d

Su, Y. C., Tsui, C. H., Tsai, C. Y., and Ko, B. T. (2020b). Highly active bimetallic nickel catalysts for alternating copolymerization of carbon dioxide with epoxides. Polym. Chem. 18, 3225-3236. doi: 10.1039/d0py00174k

Tasdelen, M. A. (2011). Diels-Alder "click" reactions: recent applications in polymer and material science. Polym. Chem. 10, 2133-2145. doi: 10.1039/c1py00041a

Thevenon, A., Cyriac, A., Myers, D., White, A. J. P., Durr, C. B., and Williams, C. K. (2018). Indium catalysts for low-pressure $\mathrm{CO}_{2}$ /Epoxide ring-opening copolymerization: evidence for a mononuclear mechanism? J. Am. Chem. Soc. 140, 893-6903. doi: 10.1021/jacs.8b01920

Thevenon, A., Garden, J. A., White, A. J. P., and Williams, C. K. (2015). Dinuclear zinc salen catalysts for the ring opening copolymerization of epoxides and carbon dioxide or anhydrides. Inorg. Chem. 24, 11906-11915. doi: 10.1021/acs.inorgchem.5b02233 
Trott, G., Garden, J. A., and Williams, C. K. (2019). Heterodinuclear zinc and magnesium catalysts for epoxide $/ \mathrm{CO}_{2}$ ring opening copolymerizations. Chem. Sci. 17, 4618-4627. doi: 10.1039/c9sc00385a

Tsai, C. Y., Cheng, F. Y., Lu, K. Y., Wu, J. T., Huang, B. H., Chen, W. A., et al. (2016). Dinuclear and trinuclear nickel complexes as effective catalysts for alternating copolymerization on carbon dioxide and cyclohexene oxide. Inorg. Chem. 16, 7843-7851. doi: 10.1021/acs.inorgchem.6b00478

Wang, B., Ji, H. Y., and Li, Y. S. (2020). Lewis pairs catalytic ringopening polymerization of cyclic ester and ring-opening alternating copolymerization of cyclic anhydride/epoxide. Acta Polym. Sin. 10, 1104-1120. doi: 10.11777/j.issn1000-3304.2020.20111

Wang, S., and Urban, M. W. (2020). Self-healing polymers. Nat. Rev. Mater. 8, 562-583. doi: 10.1038/s41578-020-0202-4

Wang, Y., Fan, J., and Darensbourg, D. J. (2015). Construction of versatile and functional nanostructures derived from $\mathrm{CO}_{2}$-based polycarbonates. Angew. Chem. Int. Ed. 35, 10206-10210. doi: 10.1002/anie.201505076

Wang, Z., Hu, M., Hu, S., Han, J., Wang, Z., Chen, Y., et al. (2018). Facile one-pot synthesis of multifunctional polyphosphazene nanoparticles as multifunctional platform for tumor imaging. Anal. Bioanal. Chem. 16, 3723-3730. doi: 10.1007/s00216-018-1035-5

Xia, Y., and Zhao, J. (2018). Macromolecular architectures based on organocatalytic ring-opening (co)polymerization of epoxides. Polymer 143, 343-361. doi: 10.1016/j.polymer.2018.03.047

Xu, Y., Zhou, F., Zhou, D., Mo, J., Hu, H., Lin, L., et al. (2020). Degradation behaviors of biodegradable aliphatic polyesters and polycarbonates. J. Biobased Mater. Bioenergy 14, 155-168. doi: 10.1166/jbmb.2020.195

Yang, G. W., and Wu, G. P. (2019). High-efficiency construction of $\mathrm{CO}_{2}$-based healable thermoplastic elastomers via a tandem synthetic strategy. ACS Sustain. Chem. Eng. 1, 1372-1380. doi: 10.1021/acssuschemeng.8b05084

Yang, G. W., Zhang, Y. Y., Wang, Y., Wu, G. P., Xu, Z. K., and Darensbourg, D. J. (2018). Construction of autonomic self-Healing $\mathrm{CO}_{2}$-based polycarbonates via one-pot tandem synthetic strategy. Macromolecules 4, 1308-1313. doi: 10.1021/acs.macromol.7b02715

Ye, S., Wang, S., Lin, L., Xiao, M., and Meng, Y. (2019). CO 2 derived biodegradable polycarbonates: synthesis, modification and applications. Adv. Ind. Eng. Polym. Res. 4, 143-160. doi: 10.1016/j.aiepr.2019.09.004

Ye, S., Wang, W., Liang, J., Wang, S., Xiao, M., and Meng, Y. (2020). Metalfree approach for a one-pot construction of biodegradable block copolymers from epoxides, phthalic anhydride, and $\mathrm{CO}_{2}$. ACS Sustain. Chem. Eng. 48, 17860-17867. doi: 10.1021/acssuschemeng.0c07283

Yi, N., Chen, T. T. D., Unruangsri, J., Zhu, Y., and Williams, C. K. (2019). Orthogonal functionalization of alternating polyesters: selective patterning of $(\mathrm{AB}) \mathrm{n}$ sequences. Chem. Sci. 43, 9974-9980. doi: 10.1039/ c9sc03756j

Yi, N., Unruangsri, J., Shaw, J., and Williams, C. K. (2015). Carbon dioxide capture and utilization: using dinuclear catalysts to prepare polycarbonates. Faraday Discuss. 183, 67-82. doi: 10.1039/c5fd00073d
Yoshida, H., and Takenaka, M. (2015). "Physics of block copolymers from bulk to thin films," in Directed Self-assembly of Block Co-polymers for Nano-manufacturing. Woodhead Publishing Series in Electronic and Optical Materials, eds R. Gronheid and P. Nealey (Sawston; Cambridge: Woodhead Publishing), 3-26. doi: 10.1016/b978-0-08-100250-6.00001-8

Yu, C. Y., Chuang, H. J., and Ko, B. T. (2016). Bimetallic bis(benzotriazole iminophenolate) cobalt, nickel and zinc complexes as versatile catalysts for coupling of carbon dioxide with epoxides and copolymerization of phthalic anhydride with cyclohexene oxide. Catal. Sci. Technol. 6, 1779-1791. doi: $10.1039 / \mathrm{c} 5$ cy01290b

Zhang, B., Li, H., Luo, H., and Zhao, J. (2020a). Ring-opening alternating copolymerization of epichlorohydrin and cyclic anhydrides using singleand two-component metal-free catalysts. Eur. Polym. J. 134: 109820 doi: 10.1016/j.eurpolymj.2020.109820

Zhang, J., Wang, L., Liu, S., Kang, X., and Li, Z. (2021). A lewis pair as organocatalyst for one-pot synthesis of block copolymers from a mixture of epoxide, anhydride, and $\mathrm{CO}_{2}$. Macromolecules, 54, 763-772. doi: 10.1021/acs.macromol.0c02647

Zhang, J., Wang, L., Liu, S., and Li, Z. (2020b). Phosphazene/lewis acids as highly efficient cooperative catalyst for synthesis of high-molecular-weight polyesters by ring-opening alternating copolymerization of epoxide and anhydride. $J$. Polym. Sci. 6, 803-810. doi: 10.1002/pol.20190175

Zhou, Y., Duan, R., Li, X., Pang, X., Wang, X., and Chen, X. (2017). Preparation and thermal properties of polycarbonates/esters catalyzed by using dinuclear salph$\mathrm{Al}$ from ring-opening polymerization of epoxide monomers. Chem. Asian J. 24, 3135-3140. doi: 10.1002/asia.201701048

Zhu, S., Wang, Y., Ding, W., Zhou, X., Liao, Y., and Xie, X. (2020). Lewis pair catalyzed highly selective polymerization for the one-step synthesis of $\mathrm{A}(\mathrm{z}) \mathrm{C}(\mathrm{y})(\mathrm{AB})(\mathrm{x}) \mathrm{C}(\mathrm{y}) \mathrm{A}(\mathrm{z})$ pentablock terpolymers. Polym. Chem. 10, 1691-1695. doi: 10.1039/c9py01508f

Zhu, Y., Poma, A., Rizzello, L., Gouveia, V. M., Ruiz-Perez, L., Battaglia, G., et al. (2019). Metabolically active, fully hydrolysable polymersomes. Angew. Chem. Int. Ed. 14, 4581-4586. doi: 10.1002/anie.201814320

Zhu, Y., Romain, C., and Williams, C. K. (2015). Selective polymerization catalysis: controlling the metal chain end group to prepare block copolyesters. J. Am. Chem. Soc. 38, 12179-12182. doi: 10.1021/jacs.5b04541

Conflict of Interest: The authors declare that the research was conducted in the absence of any commercial or financial relationships that could be construed as a potential conflict of interest.

Copyright (c) 2021 Liang, Tan and Zhu. This is an open-access article distributed under the terms of the Creative Commons Attribution License (CC BY). The use, distribution or reproduction in other forums is permitted, provided the original author(s) and the copyright owner(s) are credited and that the original publication in this journal is cited, in accordance with accepted academic practice. No use, distribution or reproduction is permitted which does not comply with these terms. 